\title{
Immersion mode heterogeneous ice nucleation by an illite rich powder representative of atmospheric mineral dust
}

\author{
S. L. Broadley, B. J. Murray, R. J. Herbert, J. D. Atkinson, S. Dobbie, T. L. Malkin, E. Condliffe, and L. Neve \\ School of Earth and Environment, University of Leeds, Leeds, LS2 9JT, UK \\ Correspondence to: B. J. Murray (b.j.murray@leeds.ac.uk)
}

Received: 22 July 2011 - Published in Atmos. Chem. Phys. Discuss.: 12 August 2011

Revised: 5 December 2011 - Accepted: 12 December 2011 - Published: 5 January 2012

\begin{abstract}
Atmospheric dust rich in illite is transported globally from arid regions and impacts cloud properties through the nucleation of ice. We present measurements of ice nucleation in water droplets containing known quantities of an illite rich powder under atmospherically relevant conditions. The illite rich powder used here, NX illite, has a similar mineralogical composition to atmospheric mineral dust sampled in remote locations, i.e. dust which has been subject to long range transport, cloud processing and sedimentation. Arizona Test Dust, which is used in other ice nucleation studies as a model atmospheric dust, has a significantly different mineralogical composition and we suggest that NX illite is a better surrogate of natural atmospheric dust.

Using optical microscopy, heterogeneous nucleation in the immersion mode by NX illite was observed to occur dominantly between $246 \mathrm{~K}$ and the homogeneous freezing limit. In general, higher freezing temperatures were observed when larger surface areas of NX illite were present within the drops. Homogenous nucleation was observed to occur in droplets containing low surface areas of NX illite. We show that NX illite exhibits strong particle to particle variability in terms of ice nucleating ability, with $\sim 1$ in $10^{5}$ particles dominating ice nucleation when high surface areas were present. In fact, this work suggests that the bulk of atmospheric mineral dust particles may be less efficient at nucleating ice than assumed in current model parameterisations.

For droplets containing $\leq 2 \times 10^{-6} \mathrm{~cm}^{2}$ of NX illite, freezing temperatures did not noticeably change when the cooling rate was varied by an order of magnitude. The data obtained during cooling experiments (surface area $\leq 2 \times 10^{-6} \mathrm{~cm}^{2}$ ) is shown to be inconsistent with the single component stochastic model, but is well described by the singular model $\left(n_{s}(236.2 \mathrm{~K} \leq T \leq 247.5 \mathrm{~K})=\exp \left(6.53043 \times 10^{4}-8.2153088\right.\right.$
\end{abstract}

$\left.\times 10^{2} T+3.446885376 T^{2}-4.822268 \times 10^{-3} T^{3}\right)$. However, droplets continued to freeze when the temperature was held constant, which is inconsistent with the time independent singular model. We show that this apparent discrepancy can be resolved using a multiple component stochastic model in which it is assumed that there are many types of nucleation sites, each with a unique temperature dependent nucleation coefficient. Cooling rate independence can be achieved with this time dependent model if the nucleation rate coefficients increase very rapidly with decreasing temperature, thus reconciling our measurement of nucleation at constant temperature with the cooling rate independence.

\section{Introduction}

Ice formation is difficult to quantitatively understand in the Earth's atmosphere. This is in part because it is governed by kinetics, with phase changes only occurring under nonequilibrium conditions (Martin, 2000). Water droplets suspended in the atmosphere are known to supercool to about $236 \mathrm{~K}$, but ice formation can be catalysed at much higher temperatures by the presence of solid particles termed ice nuclei (IN). These IN are rare in comparison to cloud condensation nuclei (which form liquid droplets) and heterogeneous ice nucleation can therefore result in a cloud composed of a smaller number of larger particles since ice particles grow at the expense of supercooled liquid droplets (Pruppacher and Klett, 1997; DeMott et al., 2010). Ice nucleation affects precipitation, cloud lifetimes and radiative properties (Denman et al., 2007). Hence, understanding heterogeneous freezing is an important factor in correctly predicting cloud properties, their impact on climate and their response to human activities. 


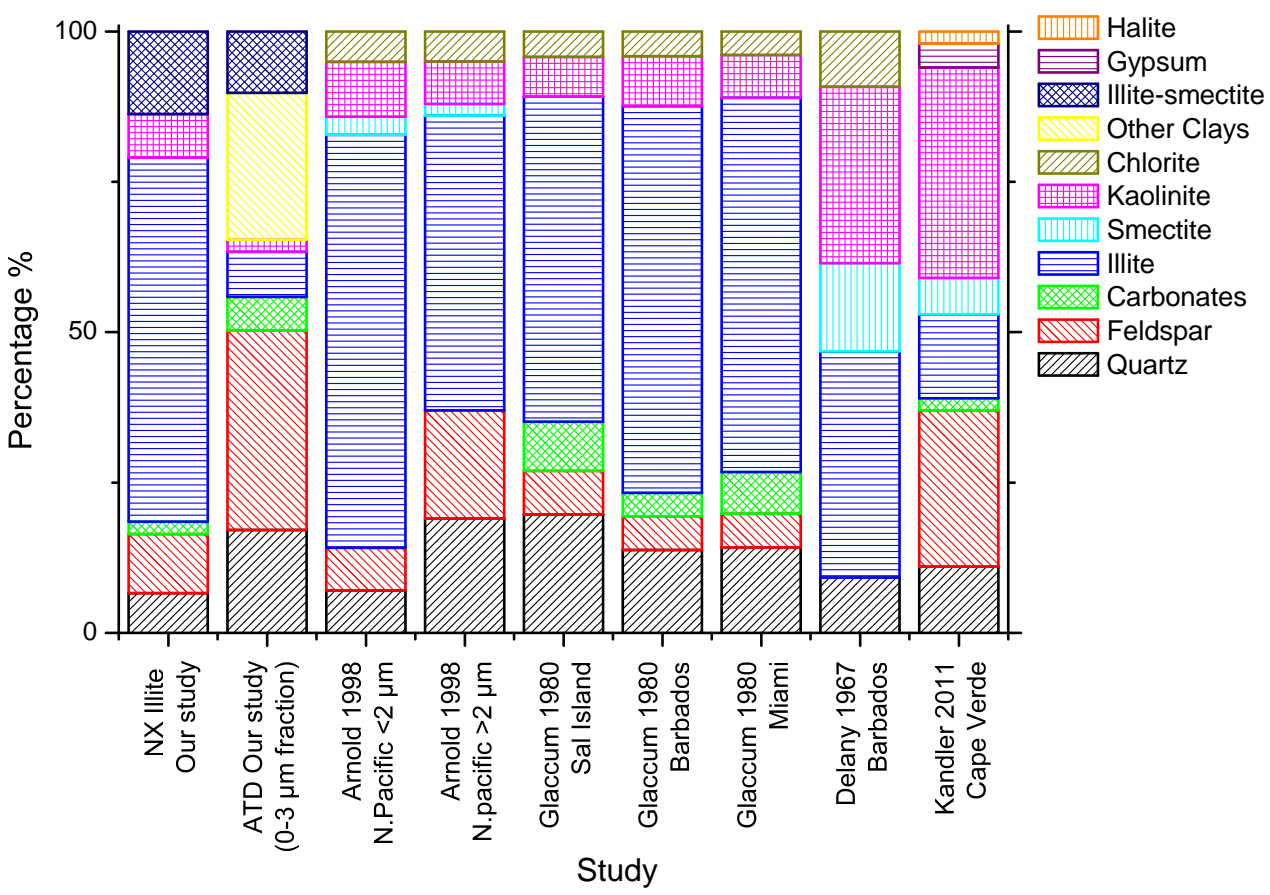

Fig. 1. Summary of mineralogical composition of NX illite, Arizona Test Dust and samples of airborne dust collected some distance from the source regions. See Table 1 for corresponding values.

Atmospheric IN in mixed phase clouds are composed of a range of materials including mineral dust, metallic solids, soot, volcanic ash and biogenic material (Mason, 1971; Pruppacher and Klett, 1997). Several field studies have shown mineral dust to be a particularly important class of IN (Pratt et al., 2009; Richardson et al., 2007; DeMott et al., 2003a; DeMott et al., 2003b). For example, Richardson et al. (2007) found that for mixed phase clouds in the western United States about a third of all IN were mineral dust, even though mineral dust contributed only a few percent to the total background aerosol.

Heterogeneous ice nucleation has been hypothesised to occur in four different modes: deposition, condensation, immersion, and contact (Vali, 1985). Deposition mode nucleation involves deposition of ice onto the solid surface directly from the vapour phase, and can occur when conditions are supersaturated with respect to ice. Immersion freezing occurs when ice nucleates on a solid particle immersed in a supercooled liquid droplet, whereas condensation freezing involves ice formation during the condensation of liquid water onto to a solid particle. Contact freezing occurs when a solid particle comes into contact with the water-air interface. Generally, contact nucleation has been observed to occur at higher temperatures than immersion freezing for the same IN (Shaw et al., 2005; Durant and Shaw, 2005; Fornea et al., 2009).
Currently, the relative importance of these freezing modes in the atmosphere is uncertain. Immersion mode and contact freezing are thought to be most important in many mixed phase clouds (Lohmann and Diehl, 2006; de Boer et al., 2010; Hoose et al., 2008), while deposition mode freezing may be more important in upper tropospheric ice clouds (DeMott, 2002). In addition, recent modelling studies indicate that freezing in the immersion mode occurs dominantly on mineral dust (Hoose et al., 2010; Diehl and Wurzler, 2010; Hoose et al., 2008).

The radiative forcing due to ice nucleation by clay minerals in a global climate modelling sensitivity study was found to be comparable to the forcing by anthropogenic $\mathrm{CO}_{2}$ (Lohmann and Diehl, 2006). In addition, Lohmann and Diehl (2006) found that there was a strong sensitivity to dust type, using parameterisations based upon experimental data of freezing due to montmorillonite and kaolinite. Although montmorillonite and kaolinite are both present in the atmosphere, illite has often been observed to be the most abundant airborne clay mineral (Chester et al., 1972; Glaccum and Prospero, 1980; Delany et al., 1967; Arnold et al., 1998). This is illustrated in Fig. 1 (and Table 1), which lists the mineralogical composition of atmospheric dust sampled a substantial distance (100s to 1000 s of miles) from the source regions. For example, Glaccum and Prospero (1980) found that Saharan mineral dust samples collected in the Caribbean were composed of $\sim 64 \%$ illite and Arnold et al. (1998) found that on average, particles of $\leq 2 \mu \mathrm{m}$ in size collected over the North Pacific were composed of $68 \%$ illite. 
Table 1. Summary of mineralogical composition of NX illite, Arizona Test Dust and samples of airborne dust collected some distance from the source regions.

\begin{tabular}{|c|c|c|c|c|c|c|c|c|c|c|c|}
\hline Sample & Quartz & Feldspar & Carbonate & Illite & $\begin{array}{l}\text { Illite-smectite } \\
\text { mixed layer }\end{array}$ & $\begin{array}{l}\text { Smectite } \\
\text { (inc. } \\
\text { Montmorillonite) }\end{array}$ & Kaolinite & Chlorite & Other clays & Halite & Gypsum \\
\hline $\begin{array}{l}\text { NX illite } \\
\text { Our study }\end{array}$ & 6.6 & 9.8 & 2.1 & 60.5 & 13.8 & - & 7.2 & - & - & - & - \\
\hline $\begin{array}{l}\text { Arizona Test Dust } \\
(0-3 \mu \mathrm{m} \text { fraction }) \\
\text { Our study }\end{array}$ & 17.1 & 33.2 & 5.6 & 7.5 & 10.2 & - & 2 & - & 24.4 & - & - \\
\hline $\begin{array}{l}\text { (Arnold et al., 1998) } \\
\text { N.Pacific }<2 \mu \mathrm{m}\end{array}$ & 7.1 & 7.1 & - & 68.7 & - & 3 & 9.1 & 5 & - & - & - \\
\hline $\begin{array}{l}\text { (Arnold et al., 1998) } \\
\text { N.Pacific } 2-20 \mu \mathrm{m}\end{array}$ & 19 & 18 & - & 49 & - & 2 & 7 & 5 & - & - & - \\
\hline $\begin{array}{l}\text { (Glaccum and Prospero, 1980) } \\
\text { Sal island }\end{array}$ & 19.7 & 7.2 & 8.2 & 54 & - & Trace & 6.6 & 4.3 & - & - & - \\
\hline $\begin{array}{l}\text { (Glaccum and Prospero, 1980) } \\
\text { Barbados }\end{array}$ & 13.8 & 5.6 & 3.9 & 64.3 & - & Trace & 8.3 & 4.1 & - & - & - \\
\hline $\begin{array}{l}\text { (Glaccum and Prospero, 1980) } \\
\text { Miami }\end{array}$ & 14.2 & 5.6 & 6.9 & 62.3 & - & - & 7.1 & 3.9 & - & - & - \\
\hline $\begin{array}{l}\text { (Delany et al., 1967) } \\
\text { Barbados }\end{array}$ & 9.2 & - & - & 37.6 & - & 14.7 & 29.4 & 9.1 & - & - & - \\
\hline $\begin{array}{l}\text { (Kandler et al., 2011) } \\
\text { Cape Verde }\end{array}$ & 11 & 26 & 2 & 14 & - & 6 & 35 & - & - & 2 & 4 \\
\hline
\end{tabular}

Note that blank spaces indicates that the presence of that particular mineral was not reported.

Glaccum and Prospero (1980) show that minerals associated with the coarse mode, such as quartz and feldspars, are less abundant further from the source regions (Africa in this case). The process of sedimentation results in the finer grained clay minerals, such as illite and kaolinite, becoming increasingly dominant in atmospheric dust. Arizona Test Dust (ATD) has been widely used as a surrogate of atmospheric dust in ice nucleation studies, but X-ray diffraction analysis reveal that it has a substantially different composition to sampled atmospheric dusts (see Fig. 1). It is much richer in feldspars and contains a high proportion of uncommon clays. Hence, we have used an illite rich powder (referred to as NX illite by the supplier) which has a more similar mineralogical make up to dust which has undergone long range transport (see Fig. 1 and also the materials characterisation section). On this basis NX illite is a more representative surrogate for atmospheric dust than ATD.

In this paper, the ice-nucleating ability of NX illite in the immersion mode is determined as a function of surface area and the time dependence of nucleation is also investigated. The results are then interpreted using several theoretical approaches and parameterised for use in atmospheric models.

\section{Theoretical background}

In the atmosphere, ice nucleation occurs when an ice cluster of a critical size is formed from either gas-phase or liquidphase water molecules, above which size the cluster will grow spontaneously into a macroscopic crystal. The prob- ability of nucleation depends upon random fluctuations in cluster size, due to the attachment and detachment of water molecules. For homogeneous freezing of liquid droplets, the probability of a critical cluster forming is greater for larger volumes of liquid and longer periods of time. Nucleation is therefore a stochastic process. The change in number of liquid droplets $\left(n_{\text {liq }}\right)$ of volume $(V)$ with time can be written as:

$\frac{d n_{\text {liq }}}{d t}=-n_{\text {liq }} J_{\text {hom }} V$

where $J_{\text {hom }}$ is the homogeneous nucleation rate coefficient $\left(\mathrm{cm}^{-3} \mathrm{~s}^{-1}\right)$ and $t$ is time (s). Equation (1) assumes that the nucleation event in an individual droplet is independent of nucleation events in other droplets and that one nucleation event per droplet leads to freezing (Pruppacher and Klett, 1997). Integrating Eq. (1) leads to:

$f_{\text {ice }}=\frac{n_{\text {ice }}}{n}=1-\exp \left(-J_{\text {hom }} V t\right)$

where $f_{\text {ice }}$ is the fraction of frozen droplets, $n_{\text {ice }}$ is the number of droplets which froze during time period $t$, and $n$ is the total number of liquid and frozen droplets. Experimentally, $f_{\text {ice }}$ (and hence $J_{\text {hom }}$ ) can be determined using either a population of liquid droplets, or by repeatedly freezing and thawing a single sample. According to classical nucleation theory (CNT), the temperature dependent homogeneous nucleation rate coefficient can be described by:

$J_{\text {hom }}(T)=A \exp \left(-\frac{\Delta G^{*}}{k T}\right)$ 
where $A$ is a pre-exponential factor in units of $\mathrm{cm}^{-3} \mathrm{~s}^{-1}$ and $\Delta G^{*}$ is the energy barrier to nucleation.

In the case of heterogeneous nucleation, ice formation is facilitated by the presence of a surface upon which the critical clusters can grow. A number of models have been used to describe heterogeneous nucleation. The stochastic hypothesis states that the substrate enhances the efficiency of a nucleation process that still depends upon random fluctuations in cluster size and is therefore time dependent. Alternatively, it has been suggested that heterogeneous ice nucleation is dominated by the freezing characteristics of available nucleation sites, so that the stochastic nature of nucleation becomes negligible. This is the basis of the singular description. An advantage of the singular description is that it is well suited to situations where there are many types of IN present. In order to simplify the description of nucleation in atmospheric models, it has been argued that the time dependence of ice nucleation by natural atmospheric IN is negligible in comparison with particle to particle variability (Vali, 2008). In the following sections we discuss the singular and stochastic models and illustrate that under certain conditions it is necessary to account for the particle to particle variability as well as the time dependence.

\subsection{The singular model}

It is assumed in the singular model that the critical clusters form on nucleation sites at a characteristic temperature, $T_{\mathrm{c}}$, above which ice nucleation cannot occur. The temperature at which a droplet containing multiple nucleation sites freezes is determined by the nucleation site with the highest $T_{\mathrm{c}}$. The simplifying assumption in this approach is that nucleation occurs as soon as $T_{\mathrm{c}}$ is reached, i.e. there is no time dependence. This means that if the temperature is held constant, no further freezing events should occur in a population of droplets. Additionally, if a droplet is subjected to several freezing and thawing cycles, then it should always freeze at the same temperature.

If every droplet in an experiment were to contain IN with only one type of nucleation site, the singular model predicts that as the droplets are cooled, every droplet will freeze at the same time, when $T_{\mathrm{c}}$ is reached. There would be a distribution of characteristic temperatures in an experiment in which each droplet contained different IN types. Then, on cooling, the fraction of droplets that freeze by temperature $T, f_{\text {ice }}(T)$, could be described by (Connolly et al., 2009; Niedermeier et al., 2010):

$f_{\text {ice }}(T)=\frac{n_{\text {ice }}(T)}{n}=1-\exp \left(-n_{s}(T) s\right)$

where $n_{\text {ice }}(T)$ is the total number of frozen droplets at temperature $T$ and $n_{s}(T)$ is the number of active sites per surface area $(s)$ that are active between $273 \mathrm{~K}$ and temperature $T$ (termed the ice-active surface site density). The density of surface sites that become active as the temperature is lowered by $d T, k(T)$, is related to $n_{s}(T)$ by:

$n_{s}(T)=-\int_{T_{0}}^{T} k(T) \cdot d T$

where $T_{0}$ is $273 \mathrm{~K}$. Note, $n_{S}(T)$ and $k(T)$ are analogous to the cumulative nucleus spectrum $(K(T))$ and differential nucleus spectrum $(k(T))$ previously defined by Vali (1971), but here are expressed in terms of surface area rather than droplet volume. While the singular model is convenient and may be a good approximation under many atmospheric conditions, time dependence of nucleation may be important in some cloud types (Crosier et al., 2011).

\subsection{The single component stochastic model}

In this approach it is assumed that nucleation sites enhance the efficiency of nucleation, but that nucleation still depends upon random fluctuations in cluster size and so is a probabilistic, time-dependent process. According to this model, droplet freezing should exhibit cooling rate dependence and nucleation should continue at constant temperature. Therefore, heterogeneous nucleation can be treated analogously to homogeneous nucleation. If each droplet contains the same number of identical nucleation sites (i.e. a single "component") then the change in number of liquid droplets with time can be written as:

$\frac{d n_{\text {liq }}}{d t}=-n_{\text {liq }} J_{\text {het }} s$

where $s$ is the unit surface area of IN per droplet $\left(\mathrm{cm}^{2}\right)$ and $J_{\text {het }}$ is the heterogeneous nucleation rate coefficient $\left(\mathrm{cm}^{-2}\right.$ $\mathrm{s}^{-1}$ ). Integrating Eq. (6) results in:

$f_{\text {ice }}=\frac{n_{\text {ice }}}{n}=1-\exp \left(-J_{\text {het }} s t\right)$

In addition, CNT can be extended to heterogeneous nucleation:

$J_{\text {het }}(T)=A_{\text {het }} \exp \left(-\frac{\Delta G^{*} \varphi}{k T}\right)$

where $A_{\text {het }}$ is a pre-exponential factor in units of $\mathrm{cm}^{-2} \mathrm{~s}^{-1}$ and $\varphi$ is the factor by which the presence of a solid surface reduces the height of the energy barrier relative to homogeneous nucleation. Assuming that the ice cluster is a spherical cap in contact with a flat surface, $\varphi$ can be calculating using the following expression:

$\varphi=\frac{(2+\cos \theta)(1-\cos \theta)^{2}}{4}$

where $\theta$ is the contact angle between the ice nucleus and the surface. While $\theta$ has limited physical meaning since the ice nucleus is unlikely to take on a spherical form, it provides a useful relative measure of a substance's ability to nucleate ice. 


\subsection{Methods of combining time dependence with particle to particle variability}

Early work by Vali and Stansbury (1966) on the freezing behaviour of distilled droplets containing unknown IN found the experimental results to be inconsistent with the singlecomponent stochastic model. Although nucleation continued with time during isothermal experiments, the number of liquid droplets did not decay exponentially with time, as would be expected for stochastic nucleation by a single type of nucleation site. In addition, these droplets exhibited cooling rate dependence, which is also inconsistent with the singular model. Therefore, Vali and Stansbury (1966) proposed that the characteristics of a nucleation site determines the mean temperature at which nucleation can occur (similar to the singular model), but that nucleation may occur at slightly higher or lower temperatures due to the stochastic nature of nucleation. More recently, Vali $(1994,2008)$ has extended this idea.

Vali (1994) modified the singular model empirically in order to account for the experimentally observed cooling rate dependence of droplet freezing temperatures:

$n_{\text {ice }}(T)=n \exp (-K(T-\alpha) V)$

where $K(T)$ is the cumulative nucleus spectrum (analogous to $n_{s}(T)$, expressed per unit volume) and $\alpha$ is a temperature offset. The variable $\alpha$ is related to the cooling rate $(r)$ with an empirical parameter $\beta$ :

$\alpha=\beta \log (|r|)$

Vali (1994) calculated $\beta$ to be 0.66 based on earlier observations (Vali and Stansbury, 1966) of a $0.2 \mathrm{~K}$ change in mean freezing temperature with a factor of two change in cooling rate for the freezing of distilled water droplets.

In a later study, Vali (2008) was able to calculate nucleation rates as a function of the temperature difference from the characteristic temperature of the nuclei, by observing the freezing temperatures of individual droplets which were subjected to multiple freezing and thawing cycles. These droplets contained soil samples (with many components) and the freezing temperatures of different droplets ranged from $267 \mathrm{~K}$ to $249 \mathrm{~K}$. However, the changes in freezing temperatures of individual droplets between cycles were generally $\leq 1 \mathrm{~K}$, which highlighted the dominance of particle to particle variability in nucleation. The time dependent nature of nucleation was illustrated by an observed $0.4 \mathrm{~K}$ shift in freezing temperatures when the cooling rate was increased by a factor of six.

The idea that droplets may contain several IN/nucleation site types, each with a characteristic nucleation rate, has also been applied to experimental data by including more than one component in the stochastic equation (Eq. 6), leading to the multiple-component stochastic model. For example, Stoyanova et al. (1994) had to apply a multiple-component stochastic model to be able to model freezing of droplets containing dust collected from an urban location. They assumed that three materials with three distinct contact angles dominated ice nucleation. Additionally, Marcolli et al. (2007) found that the freezing behaviour of droplets containing Arizona Test Dust could not be described by assuming that all particles were characterised by a single contact angle but that a distribution of contact angles between particles was required. A form of the multiple component stochastic model has very recently been described by Niedermeier et al. (2011), who presented a conceptual 'soccer ball' model in which a particle's surface was divided into separate patches whose properties were defined by a particular contact angle. The application of the multiple component stochastic model to various atmospheric scenarios has been discussed in detail by Murray et al. (2011b) and will be applied to ice nucleation by NX illite later in this paper.

\section{Experimental}

The experimental set-up has been used previously to look at both homogenous and heterogeneous ice nucleation (Murray et al., 2010, 2011a, b), as well as phase changes in iodine oxide particles (Kumar et al., 2010). It consists of a custom made cold stage coupled to a commercial optical transmission microscope with a 10x objective. The droplets were supported on a hydrophobic surface on the cold stage, which could be cooled at a controlled rate or held at a single temperature. Temperature measurements were made using $\mathrm{K}$ type thermocouples positioned in the cold stage, as close as possible to the droplets (see Murray et al. (2010) for further details). The uncertainty in temperature was $0.6 \mathrm{~K}$, with an estimated reproducibility of $0.3 \mathrm{~K}$ (Murray et al., 2010).

Water droplets containing clay particles were produced from a dust-in-water suspension of a known concentration using a custom made nebuliser (Murray et al., 2011b; Pant et al., 2006). The droplets were deposited on a glass cover slip inside a chamber maintained at saturation, so that the droplets did not grow or shrink through evaporation or condensation once they exited the nebuliser. The concentration of NX illite in the droplet was then assumed to be the same as that of the suspension. The concentration of clay in the suspensions was determined gravimetrically and the dust was suspended by mixing for at least $12 \mathrm{~h}$ with a magnetic stirring bead. Freezing experiments were performed for NX illite concentrations between 0.006 and $1.44 \mathrm{wt} \%$. Additional experiments were also performed using a mixture of $\mathrm{NX}$ illite and kaolinite and for droplets containing no solid inclusions.

After nebulisation, a drop of silicone oil was placed over the deposited droplets and the cover slip was transferred to the cold stage. The silicone oil reduced the rate of mass transfer from supercooled water droplets to ice particles during experiments, compared to experiments performed in an $\mathrm{N}_{2}$ atmosphere, which allowed for a greater range of cooling 
Table 2. Summary of experimental conditions for runs performed using a cooling rate of $5 \mathrm{~K} \mathrm{~min}^{-1}$. Droplet distributions were split into size bins, which are labelled $\mathrm{a}, \mathrm{b}$ and $\mathrm{c}$. The median freezing temperatures for each run are also presented.

\begin{tabular}{|c|c|c|c|c|c|c|c|}
\hline $\begin{array}{l}\text { Experiment } \\
\text { number }\end{array}$ & $\begin{array}{l}\text { Concentration/ } \\
\text { wt } \%\end{array}$ & $\begin{array}{l}\text { Size Bin/ } \\
\mu \mathrm{m}\end{array}$ & $\begin{array}{l}\text { Cooling rate/ } \\
\mathrm{K} \mathrm{min}^{-1}\end{array}$ & $\begin{array}{l}\text { Median } \\
\text { volume }^{1} / \\
\mathrm{cm}^{3}\end{array}$ & $\begin{array}{l}\text { Surface area } \\
\text { of clay per } \\
\text { droplet } / \mathrm{cm}^{2}\end{array}$ & $\begin{array}{l}\text { Number of } \\
\text { droplets }\end{array}$ & $\begin{array}{l}\text { Median freezing } \\
\text { temperature/K }\end{array}$ \\
\hline $\begin{array}{l}1 \mathrm{a} \\
\mathrm{b}\end{array}$ & 0.007 & $\begin{array}{l}10-20 \\
21-40\end{array}$ & 5.0 & $\begin{array}{l}1.21 \times 10^{-9} \\
5.10 \times 10^{-9}\end{array}$ & $\begin{array}{l}9.06 \times 10^{-8} \\
3.82 \times 10^{-7}\end{array}$ & $\begin{array}{l}71 \\
17\end{array}$ & $\begin{array}{l}236.3 \\
239.7\end{array}$ \\
\hline $\begin{array}{l}2 \mathrm{a} \\
\mathrm{b}\end{array}$ & 0.009 & $\begin{array}{l}10-20 \\
21-30\end{array}$ & 5.0 & $\begin{array}{l}1.53 \times 10^{-9} \\
6.12 \times 10^{-9}\end{array}$ & $\begin{array}{l}1.42 \times 10^{-7} \\
5.70 \times 10^{-7}\end{array}$ & $\begin{array}{l}181 \\
38\end{array}$ & $\begin{array}{l}238.6 \\
239.9\end{array}$ \\
\hline $\begin{array}{l}3 \mathrm{a} \\
\mathrm{b}\end{array}$ & 0.03 & $\begin{array}{l}8-24 \\
36-56\end{array}$ & 5.0 & $\begin{array}{l}1.99 \times 10^{-9} \\
3.65 \times 10^{-8}\end{array}$ & $\begin{array}{l}6.55 \times 10^{-7} \\
1.20 \times 10^{-5}\end{array}$ & $\begin{array}{l}71 \\
8\end{array}$ & $\begin{array}{l}241.1 \\
245.4\end{array}$ \\
\hline 4 & 0.052 & $10-20$ & 5.0 & $1.32 \times 10^{-9}$ & $7.11 \times 10^{-7}$ & 123 & 242.3 \\
\hline $\begin{array}{l}5 \mathrm{a} \\
\mathrm{b}\end{array}$ & 0.066 & $\begin{array}{l}10-20 \\
21-40\end{array}$ & 5.1 & $\begin{array}{l}1.51 \times 10^{-9} \\
8.20 \times 10^{-9}\end{array}$ & $\begin{array}{l}1.04 \times 10^{-6} \\
5.65 \times 10^{-6}\end{array}$ & $\begin{array}{l}108 \\
25\end{array}$ & $\begin{array}{l}242.6 \\
244.3\end{array}$ \\
\hline $\begin{array}{l}6 \mathrm{a} \\
\mathrm{b}\end{array}$ & 0.15 & $\begin{array}{l}10-20 \\
21-32\end{array}$ & 5.0 & $\begin{array}{l}1.28 \times 10^{-9} \\
4.72 \times 10^{-9}\end{array}$ & $\begin{array}{l}2.02 \times 10^{-6} \\
7.42 \times 10^{-6}\end{array}$ & $\begin{array}{l}158 \\
31\end{array}$ & $\begin{array}{l}242.9 \\
243.7\end{array}$ \\
\hline $\begin{array}{l}7 \mathrm{a} \\
\mathrm{b} \\
\mathrm{c}\end{array}$ & 0.63 & $\begin{array}{l}10-20 \\
21-40 \\
42-52\end{array}$ & 4.8 & $\begin{array}{l}1.19 \times 10^{-9} \\
1.58 \times 10^{-8} \\
3.48 \times 10^{-8}\end{array}$ & $\begin{array}{l}7.79 \times 10^{-6} \\
7.51 \times 10^{-5} \\
2.24 \times 10^{-4}\end{array}$ & $\begin{array}{l}115 \\
16 \\
8\end{array}$ & $\begin{array}{l}243.3 \\
245.3 \\
245.6\end{array}$ \\
\hline 8 & 0.99 & $10-20$ & 4.9 & $1.17 \times 10^{-9}$ & $1.20 \times 10^{-5}$ & 153 & 243.1 \\
\hline $\begin{array}{l}9 \mathrm{a} \\
\mathrm{b}\end{array}$ & 1.44 & $\begin{array}{l}8-24 \\
30-50\end{array}$ & 5.0 & $\begin{array}{l}2.61 \times 10^{-9} \\
1.84 \times 10^{-8}\end{array}$ & $\begin{array}{l}3.92 \times 10^{-5} \\
2.77 \times 10^{-4}\end{array}$ & $\begin{array}{l}32 \\
4\end{array}$ & $\begin{array}{l}243.2 \\
245.4\end{array}$ \\
\hline
\end{tabular}

${ }^{1}$ The median droplet volume taking into account the contact angle of the droplets with the surface.

rates to be explored (Murray et al., 2011b). In this work, cooling rates between 0.8 and $10.3 \mathrm{~K} \mathrm{~min}^{-1}$ were applied. In addition, several isothermal experiments were performed in which the droplets were cooled and then held at a single temperature for a period of time, before cooling was resumed. During the experiments, images of the droplets were recorded onto DVD using a camera coupled to the microscope. Freezing events were identified by the sudden appearance of structure within the droplets. In some cases, freezing resulted in a needle of ice breaking out of the frozen droplet and coming into contact with a supercooled water droplet, inducing freezing in the second droplet. Droplets frozen in this way were disregarded. During analysis the droplets were split into different size bins; these were chosen to best utilize the droplets available (see Tables 2-4 for the size bin and median droplet volume used in each experiment).

\subsection{Materials}

The cover slips were coated with a hydrophobic organosilane (Fluka, 5\% dimethyldichlorosilane in heptane), resulting in a droplet-slide contact angle of $100^{\circ}$ (Dymarska et al., 2006; Murray et al., 2011b). Previous measurements of homogeneous nucleation rates using pure water droplets on this substrate were in good agreement with the literature data and showed that the surface did not catalyse ice formation (Murray et al., 2010).
All freezing experiments were performed using droplets of ultra-pure water $(18.2 \mathrm{M} \Omega)$. The illite suspensions were produced using NX illite powder taken from a $2.5 \mathrm{~kg}$ bag, obtained from Arginotec (NX Nanopowder, B $+\mathrm{M}$ Nottenkämper, Munich, Germany). The NX illite + kaolinite suspension was produced using kaolinite KGa-1b (96\% purity, Clay Mineral Society). The specific surface area of $\mathrm{KGa}-1 \mathrm{~b}$ was taken to be $11.8 \pm 0.8 \mathrm{~m}^{2} \mathrm{~g}^{-1}$ (Murray et al., 2011b).

\subsection{Characterisation of NX illite}

The specific surface area of NX illite was determined to be $104.2 \pm 0.7 \mathrm{~m}^{2} \mathrm{~g}^{-1}$ by $\mathrm{N}_{2}$-absorption using the BET method. This is similar to previous BET measurements of $94 \mathrm{~m}^{2} \mathrm{~g}^{-1}$ for NX illite (Steudel et al., 2009), and a value of 112.8 \pm $0.7 \mathrm{~m}^{2} \mathrm{~g}^{-1}$ for natural illite samples (Alvarez-Puebla et al., 2005). However, Steudel et al. (2009) found that micro-pores contributed $14 \%$ of the specific surface area in their sample of NX illite, which may mean that our value of $104.2 \mathrm{~m}^{2} \mathrm{~g}^{-1}$ is an overestimate. In that case, we would underestimate the ice-nucleating ability of NX illite, although this uncertainty is minor in comparison to that from the droplet size distribution.

The mineralogical composition of the NX illite sample was obtained by $\mathrm{X}$-ray diffraction analysis. The general methodology has been described previously (Hillier, 2000, 1999, 2003), and is only briefly outlined here. Preferred 
Table 3. Summary of experimental conditions for runs performed using a cooling rate other than $5 \mathrm{~K} \mathrm{~min}^{-1}$. Droplet distributions were split into size bins, which are labelled $\mathrm{a}, \mathrm{b}$ and $\mathrm{c}$. The median freezing temperatures for each run are also presented.

\begin{tabular}{|c|c|c|c|c|c|c|c|}
\hline $\begin{array}{l}\text { Experiment } \\
\text { number }\end{array}$ & $\begin{array}{l}\text { Concentration/ } \\
\text { wt } \%\end{array}$ & $\begin{array}{l}\text { Size Bin/ } \\
\mu \mathrm{m}\end{array}$ & $\begin{array}{l}\text { Cooling rate/ } \\
\mathrm{K} \mathrm{min}^{-1}\end{array}$ & $\begin{array}{l}\text { Median } \\
\text { volume }^{1} / \\
\mathrm{cm}^{3}\end{array}$ & $\begin{array}{l}\text { Surface area } \\
\text { of clay per } \\
\text { droplet } / \mathrm{cm}^{2}\end{array}$ & $\begin{array}{l}\text { Number of } \\
\text { droplets }\end{array}$ & $\begin{array}{l}\text { Median freezing } \\
\text { temperature/K }\end{array}$ \\
\hline $\begin{array}{l}10 a \\
b\end{array}$ & 0.89 & $\begin{array}{l}10-20 \\
21-30\end{array}$ & 6.0 & $\begin{array}{l}1.28 \times 10^{-9} \\
4.94 \times 10^{-9}\end{array}$ & $\begin{array}{l}1.18 \times 10^{-5} \\
4.57 \times 10^{-5}\end{array}$ & $\begin{array}{l}202 \\
37\end{array}$ & $\begin{array}{l}242.3 \\
243.5\end{array}$ \\
\hline $\begin{array}{l}11 \mathrm{a} \\
\mathrm{b}\end{array}$ & 0.89 & $\begin{array}{l}10-20 \\
21-30\end{array}$ & 1.0 & $\begin{array}{l}1.52 \times 10^{-9} \\
5.48 \times 10^{-9}\end{array}$ & $\begin{array}{l}1.41 \times 10^{-5} \\
5.07 \times 10^{-5}\end{array}$ & $\begin{array}{l}222 \\
64\end{array}$ & $\begin{array}{l}243.8 \\
244.6\end{array}$ \\
\hline 12 & 0.043 & $10-20$ & 7.5 & $1.20 \times 10^{-9}$ & $5.43 \times 10^{-7}$ & 67 & 242.1 \\
\hline $\begin{array}{l}13 \mathrm{a} \\
\mathrm{b}\end{array}$ & 0.043 & $\begin{array}{l}10-20 \\
21-30\end{array}$ & 0.8 & $\begin{array}{l}1.43 \times 10^{-9} \\
4.98 \times 10^{-9}\end{array}$ & $\begin{array}{l}6.43 \times 10^{-7} \\
2.24 \times 10^{-6}\end{array}$ & $\begin{array}{l}161 \\
39\end{array}$ & $\begin{array}{l}241.8 \\
243.9\end{array}$ \\
\hline $\begin{array}{l}14 \mathrm{a} \\
\mathrm{b} \\
\mathrm{c}\end{array}$ & 0.065 & $\begin{array}{l}10-20 \\
21-34 \\
42-72\end{array}$ & 6.0 & $\begin{array}{l}1.19 \times 10^{-9} \\
7.10 \times 10^{-9} \\
8.64 \times 10^{-8}\end{array}$ & $\begin{array}{l}8.06 \times 10^{-7} \\
4.82 \times 10^{-6} \\
5.87 \times 10^{-5}\end{array}$ & $\begin{array}{l}74 \\
10 \\
9\end{array}$ & $\begin{array}{l}241.2 \\
244.4 \\
245.4\end{array}$ \\
\hline $\begin{array}{l}15 \mathrm{a} \\
\mathrm{b} \\
\mathrm{c}\end{array}$ & 0.065 & $\begin{array}{l}10-20 \\
21-36 \\
44-80\end{array}$ & 1.0 & $\begin{array}{l}1.26 \times 10^{-9} \\
6.74 \times 10^{-9} \\
1.06 \times 10^{-7}\end{array}$ & $\begin{array}{l}8.54 \times 10^{-7} \\
4.58 \times 10^{-6} \\
7.19 \times 10^{-5}\end{array}$ & $\begin{array}{l}134 \\
17 \\
7\end{array}$ & $\begin{array}{l}241.8 \\
245.6 \\
246.9\end{array}$ \\
\hline 16 & 0.03 & $10-20$ & 10.3 & $9.99 \times 10^{-10}$ & $3.29 \times 10^{-7}$ & 31 & 241.6 \\
\hline $\begin{array}{l}17 \mathrm{a} \\
\mathrm{b}\end{array}$ & 0.006 & $\begin{array}{l}10-20 \\
21-40\end{array}$ & 0.99 & $\begin{array}{l}1.39 \times 10^{-9} \\
8.20 \times 10^{-9}\end{array}$ & $\begin{array}{l}8.85 \times 10^{-8} \\
5.20 \times 10^{-7}\end{array}$ & $\begin{array}{l}91 \\
37\end{array}$ & $\begin{array}{l}237.5 \\
241.1\end{array}$ \\
\hline
\end{tabular}

1 The median droplet volume taking into account the contact angle of the droplets with the surface.

Table 4. Summary of experimental conditions for both homogeneous and heterogeneous isothermal experiments.

\begin{tabular}{|c|c|c|c|c|c|c|c|}
\hline $\begin{array}{l}\text { Experiment } \\
\text { number }\end{array}$ & $\begin{array}{l}\text { Concentration/ } \\
\text { wt } \%\end{array}$ & $\begin{array}{l}\text { Size Bin/ } \\
\mu \mathrm{m}\end{array}$ & $\begin{array}{l}\text { Temperature/ } \\
\mathrm{K}\end{array}$ & $\begin{array}{l}\text { Median } \\
\text { volume }^{1} / \\
\mathrm{cm}^{3}\end{array}$ & $\begin{array}{l}\text { Surface area } \\
\text { of clay per } \\
\text { droplet } / \mathrm{cm}^{2}\end{array}$ & $\begin{array}{l}\text { Total number of } \\
\text { droplets (Num- } \\
\text { ber of frozen } \\
\text { droplets) }\end{array}$ & $\begin{array}{l}\text { Time/s } \\
\text { (min.s) }\end{array}$ \\
\hline $18 \mathrm{a}$ & 0.0 & $10-20$ & 237.7 & $1.08 \times 10^{-9}$ & n.a & $78(60)$ & $2727(45.27)$ \\
\hline $19 \mathrm{a}$ & 0.0 & $10-20$ & 237.6 & $1.27 \times 10^{-9}$ & n.a & $76(24)$ & $222(3.42)$ \\
\hline 20 & 0.049 & $10-20$ & 243.3 & $5.25 \times 10^{-10}$ & $2.65 \times 10^{-7}$ & $63(20)$ & $646(10.46)$ \\
\hline 21 & 0.078 & $10-20$ & 245.0 & $1.15 \times 10^{-9}$ & $9.28 \times 10^{-7}$ & $50(27)$ & 853 (14.13) \\
\hline
\end{tabular}

${ }^{1}$ The median droplet volume taking into account the contact angle of the droplets with the surface.

orientation of crystallites in the sample was avoided by using the spray dry method (Hillier, 1999). This involves nebulising an aqueous suspension of clay powder containing a $0.5 \%(\mathrm{w} / \mathrm{v})$ polyvinyl chloride (PVC) to produce droplets. As the droplets dry out, the PVC binds the clay particles together into spherical aggregates of $10-100 \mathrm{~s} \mu \mathrm{m}$ which are then packed into the sample holder of the X-ray diffractometer. The resulting diffraction patterns are highly reproducible and the relative intensities (areas) of the various peaks in the pattern are used together with patterns of reference samples of known composition to derive the proportions of the various minerals. Results for NX illite and ATD are shown in Table 1 and Fig. 1.

The results for NX illite (Fig. 1) are substantially different to the values supplied by the manufacturer. For example, we found that there was $61 \%$ illite rather than Arginotec's value of $86 \%$. Möhler et al. (2008) also used NX illite, which was quoted as being $77 \%$ illite, and Steudel et al. (2009) report an illite content of $76 \%$. This suggests that NX illite may be a variable material, which is possibly not surprising as it is a natural product. These results highlight the need to characterise the materials being used in ice nucleation studies.

ATD is shown to be composed dominantly of quartz, feldspars and a substantial proportion of unidentified clay minerals. Peaks at d-spacings of 11.35 and 10.6 do not correspond to any of the common clays found in natural samples, but are most likely related to rarer mixed layer clays. Also, minerals which are abundant in the natural samples, such as illite, are only present as minor constituents in ATD. This suggests that ATD is not a good proxy for atmospheric dust. $\mathrm{NX}$ illite is much closer in mineralogical composition to atmospheric samples. 


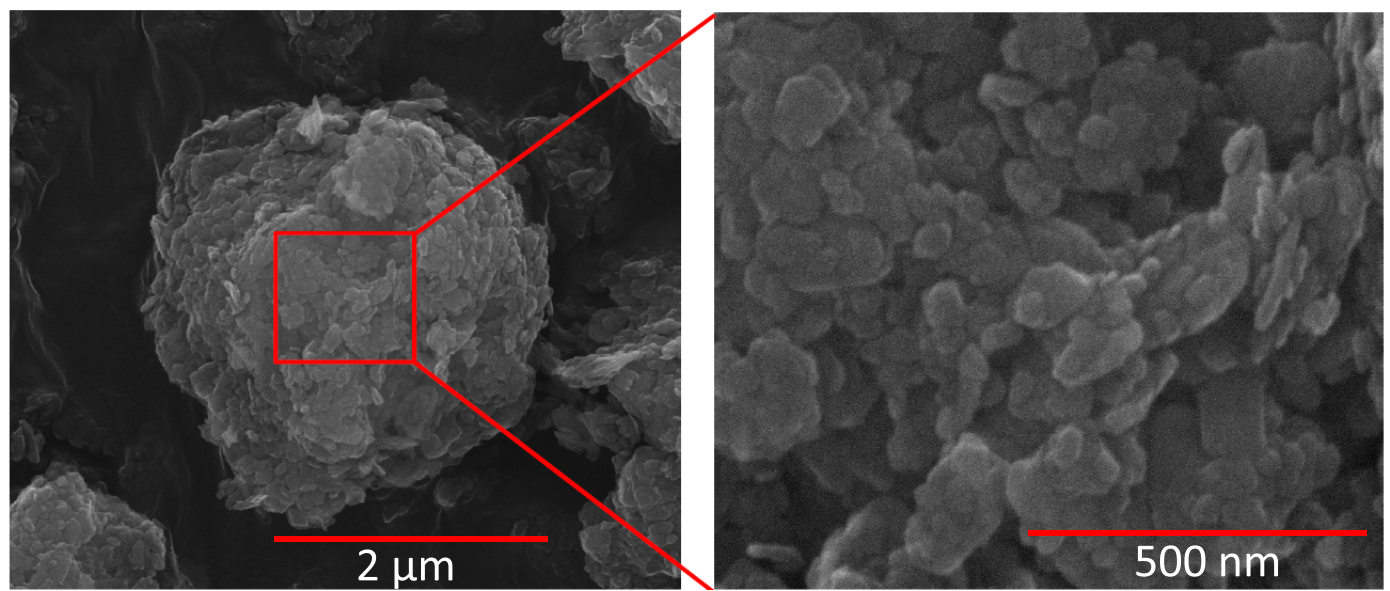

Fig. 2. Scanning Electron Microscope (SEM) images of NX illite. An aggregate of several micrometers in size is shown on the left and a close up (right) reveals that it is composed of many platelets on the order of 10-100 s of nanometres across. This is consistent with the gas adsorption measurements which suggested average particles sizes of $\sim 20 \mathrm{~nm}$ (assuming smooth spheres - see experimental section for details).

Scanning electron microscopy (using an FEI Quanta 650 FEG ESEM) was used to study the shape and size of the NX illite particles. The NX illite powder was randomly distributed on to a double sided conducting carbon pad mounted on a $10 \mathrm{~mm}$ aluminium SEM pin stub. The powder was then coated in $5 \mathrm{~nm}$ of $\mathrm{Pt} / \mathrm{Pd}$ in an Agar Scientific high resolution sputter coater. The resulting images are shown in Fig. 2. These images show that typical NX illite particles are agglomerates made up of smaller particles. A close up (right panel) reveals that the agglomerates are composed of many platelets on the order of 10-100s of nanometres across. This is similar to clay particles sampled in the atmosphere (Kandler et al., 2007; Lieke et al., 2011). Assuming the individual NX illite particles are spherical with a density of $2.7 \mathrm{~g} \mathrm{~cm}^{-3}$ (typical for clay minerals) and using the BET surface area from above, their diameter would be about $20 \mathrm{~nm}$. The SEM images clearly show the particles are non-spherical; nevertheless, the particle size based on the BET surface area is consistent with the SEM images. Energy-dispersive X-ray spectroscopy (EDX) confirmed that the agglomerates primarily consisted of illite particles.

\section{Results and discussion}

\subsection{Heterogeneous freezing temperatures}

For each cooling ramp experiment we determined the cumulative fraction of frozen droplets $\left(f_{\text {ice }}(T)\right)$ as a function of temperature:

$f_{\text {ice }}(T)=n_{\text {ice }}(T) / n$

where $n_{\text {ice }}(T)$ is the total number of frozen droplets at temperature $T$ and $n$ is the total number of frozen or liquid droplets. Figure 3 a shows the fraction frozen curves for droplets in the 10-20 $\mu \mathrm{m}$ size range for a number of NX illite concentrations (see Table 2 for a summary of the experimental parameters). These experimental runs were all performed using a cooling rate of $5 \mathrm{~K} \mathrm{~min}^{-1}$. Also shown for comparison is an experimental $f_{\text {ice }}(T)$ curve for pure water droplets for the same cooling rate $\left(5 \mathrm{~K} \mathrm{~min}^{-1}\right)$ (Murray et al., 2010), which indicates that the NX illite caused heterogeneous nucleation.

The $f_{\text {ice }}(T)$ curve for droplets containing $0.007 \mathrm{wt} \% \mathrm{NX}$ illite partially overlaps with the pure $\mathrm{H}_{2} \mathrm{O}$ curve implying that some of these droplets froze homogeneously. The number of particles per droplet can be estimated using the surface area of NX illite per droplet if the size of the NX illite particles is known. Based on the estimated size of individual NX illite particles $(20 \mathrm{~nm}$, from the BET and SEM measurements, see Sect. 3), calculations indicate that even for the lowest concentrations $(0.006 \mathrm{wt} \%)$ there should be at least $10^{3}$ of these individual particles per droplet. These individual particles may have been part of larger agglomerates and therefore each droplet may contain fewer aggregates of particles. For example, if the aggregates were $100 \mathrm{~nm}$ in diameter then there would be on the order of 100 aggregate particles per droplet. In calculations of nucleation rate and ice active surface site density later in this paper we assume that the NX-illite is evenly distributed throughout the droplets.

In general, the freezing temperature of the droplets was higher for greater NX illite concentrations (and hence greater surface areas of the clay). However, the $f_{\text {ice }}(T)$ curves show that little change in freezing temperatures occurred when increasing the concentration from $0.63 \mathrm{wt} \%$ to $1.44 \mathrm{wt} \%$.

In our experiments, the surface area of clay available in a water droplet could be increased in two ways: by increasing the concentration of the initial suspension (as in Fig. 3a), or by increasing the droplet volume. A comparison of the 

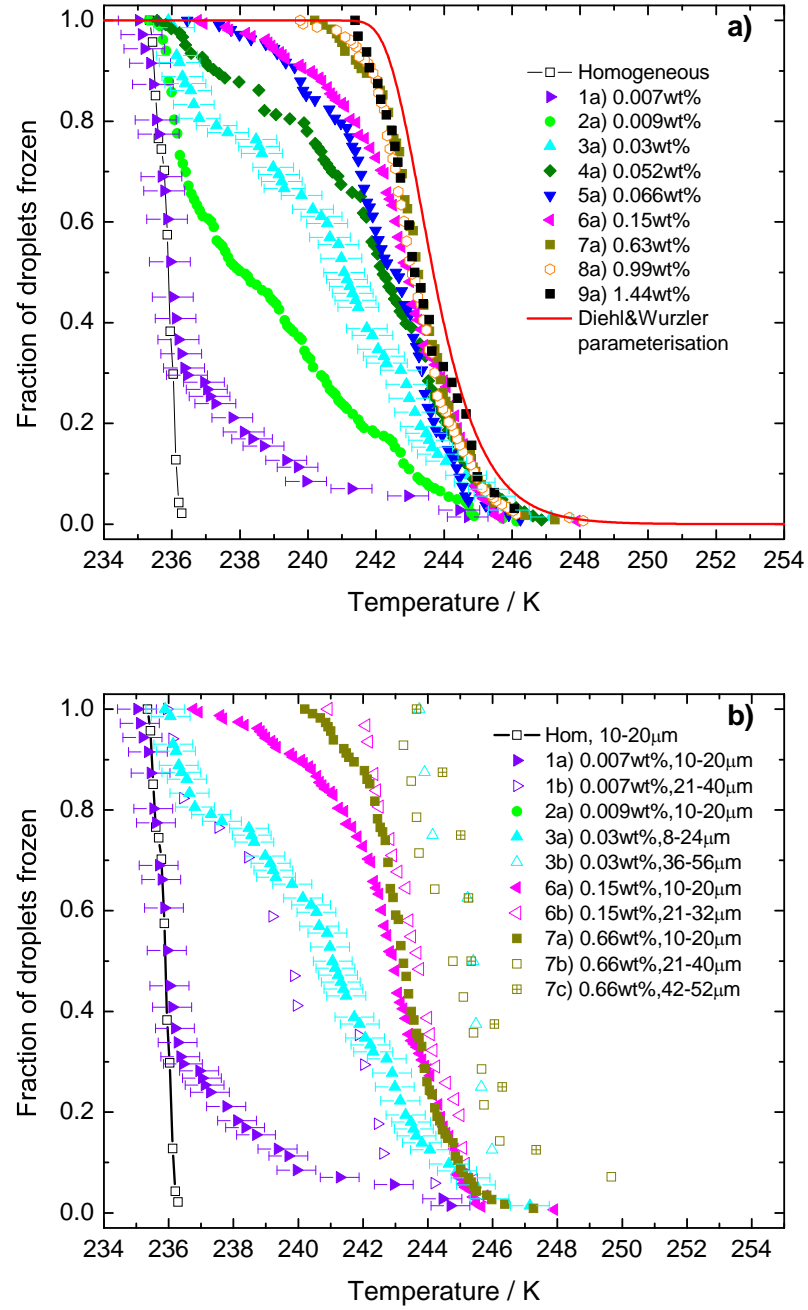

Fig. 3. (a) Fraction of droplets frozen in the $10-20 \mu \mathrm{m}$ size bin as a function of temperature for water droplets containing known concentrations of illite cooled at $5 \mathrm{~K} \mathrm{~min}^{-1}$. We also show the droplet volume dependent parameterisation of Diehl and Wurzler (2004) for $15 \mu \mathrm{m}$ droplets which is based on the data of Hoffer (1961).(b) Comparison of the fraction of droplets frozen in different size bins as a function of temperature (cooling rate $5 \mathrm{~K} \mathrm{~min}^{-1}$ ).

$f_{\text {ice }}(T)$ curves for droplets in the $10-20 \mu \mathrm{m}$ size range with $f_{\text {ice }}(T)$ curves for larger droplets containing the same wt \% of NX illite is shown in Fig. 3b. This plot shows that, for equivalent NX illite concentrations, larger droplets froze at higher temperatures than smaller droplets. This demonstrates that if the surface area of NX illite was increased by using larger droplets, then freezing occurred at higher temperatures and that this occurred irrespective of the NX illite concentration (see also Table 2).

This freezing behaviour is summarised in Fig. 4, which shows the median freezing temperature of the droplets $\left(T_{50 \%}\right)$ as a function of surface area (see also Table 2$)$. The median freezing temperature is the temperature at which

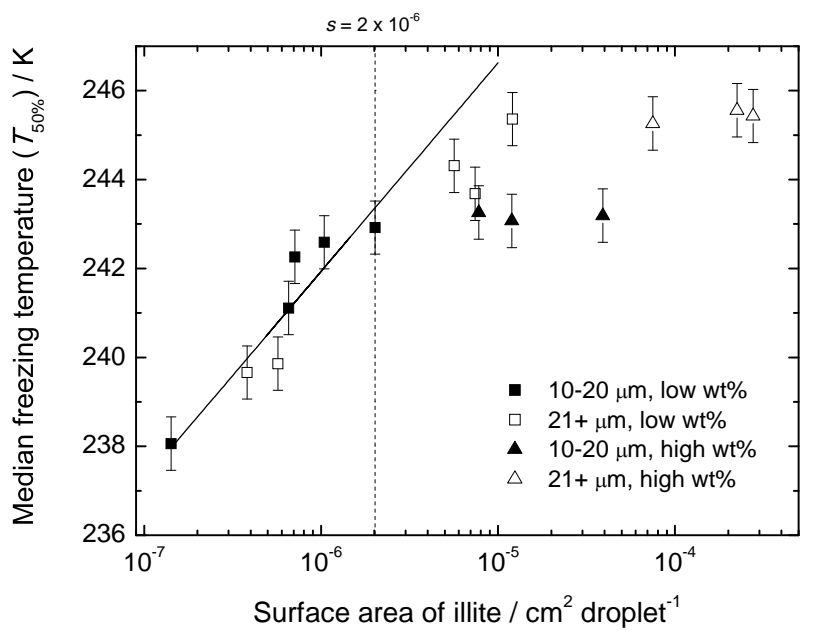

Fig. 4. The median freezing temperature $\left(T_{50} \%\right)$ as a function of NX illite surface area and droplet size for experimental runs 1-9. These runs were all performed using a cooling rate of $5 \mathrm{~K} \mathrm{~min}^{-1}$ (see Table 1 for details). For simplicity we have divided the data according to concentration and droplet size. Low wt $\%$ is defined as $\leq 0.15 \mathrm{wt} \%$; high wt $\%$ data points are for wt $\% \geq 0.63 \mathrm{wt} \%$. The dashed vertical line marks the surface area $(s)$ chosen as the upper limit to the low surface area regime (see text). Also shown is the best fit to the data in the low surface area regime (solid line).

$f_{\text {ice }}(T)=0.5$. The median surface area in an experiment was calculated from the concentration of NX illite in the droplets in combination with the specific surface area $\left(104.2 \pm 0.7 \mathrm{~m}^{2} \mathrm{~g}^{-1}\right)$ and the median droplet volume. Note that the droplet diameters quoted in this paper are the diameters measured directly from the images; however, droplet volume was calculated taking into account the contact angle of $100^{\circ}$ between the droplet and substrate.

Inspection of Fig. 4 suggests that the data can be split into two regimes. At surface areas $\leq 2 \times 10^{-6} \mathrm{~cm}^{2}, T_{50} \%$ increases approximately linearly with the log of the surface area (Fig. 4) (independent of droplet size). This behaviour is consistent with freezing probability at higher temperatures increasing with larger surface area. The behaviour for droplets containing $>2 \times 10^{-6} \mathrm{~cm}^{2}$ is more complex. For a particular size bin $T_{50 \%}$ is approximately constant (within uncertainties) on increasing the surface area. However, $T_{50} \%$ does increase for larger droplets which contain a larger surface area.

\subsection{Cooling rate dependence}

The time dependence of immersion mode nucleation by NX illite was investigated by performing experimental runs where the cooling rate was varied but the surface area (and concentration, see Table 3) was kept almost constant. Fraction frozen curves for low wt $\%$ droplets $(\sim 0.05 \mathrm{wt} \%)$ are shown in Fig. 5. For the 10-20 $\mu \mathrm{m}$ size bin data shown in 

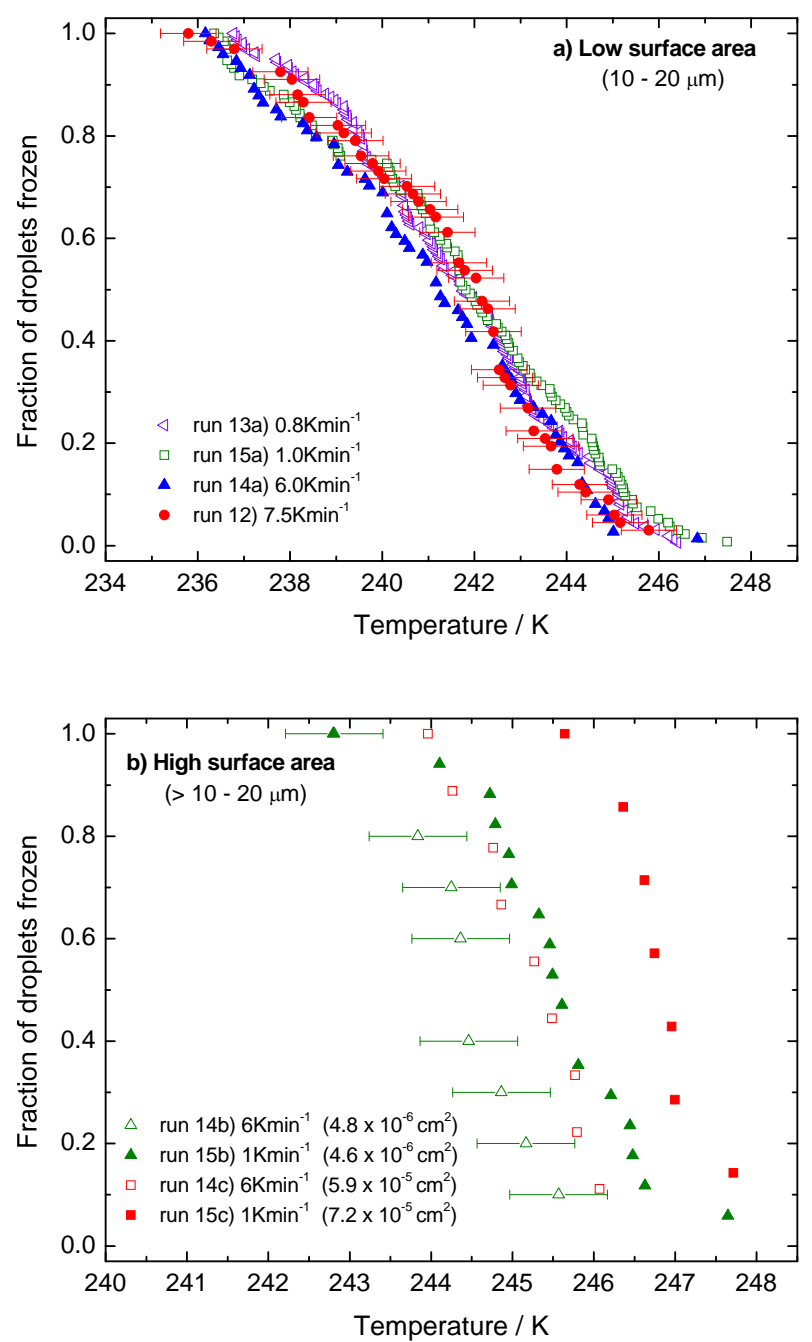

Fig. 5. (a) Fraction of frozen droplets containing $\sim 0.05 \mathrm{wt} \%$ illite as a function of cooling rate for droplets in the 10-20 $\mu \mathrm{m}$ size bin $\left(s=9.1 \times 10^{-7}-1.4 \times 10^{-6} \mathrm{~cm}^{2}\right)$. (b) Fraction of frozen droplets containing $\sim 0.05 \mathrm{wt} \%$ illite as a function of cooling rate for size bins $>10-20 \mu \mathrm{m}(14 \mathrm{~b}: 21-34 \mu \mathrm{m}, 15 \mathrm{~b}:=21-36 \mu \mathrm{m}, 14 \mathrm{c}:=42$ $72 \mu \mathrm{m}, 15 \mathrm{c}: 44-80 \mu \mathrm{m})$. See Table 3 for further details.

Fig. 5a (surface area $\sim 1 \times 10^{-6} \mathrm{~cm}^{2}$ ), varying the cooling rate between 0.8 and $7.5 \mathrm{~K} \mathrm{~min}^{-1}$ did not produce a significant change in the $f_{\text {ice }}(T)$ curves. In contrast, Fig. $5 \mathrm{~b}$ shows that larger droplets containing low NX illite concentrations appear to exhibit cooling rate dependence. For droplets containing similar surface areas of illite, the fraction frozen curves shifted to higher temperatures by $1-2 \mathrm{~K}$ when the cooling rate was reduced by a factor of six. In addition, further experiments found that for more concentrated droplets ( $0.89 \mathrm{wt} \%)$, changing the cooling rate from 6 to $1 \mathrm{~K} \mathrm{~min}^{-1}$ also shifted the $f_{\text {ice }}(T)$ curves to higher temperatures (see Table 3).
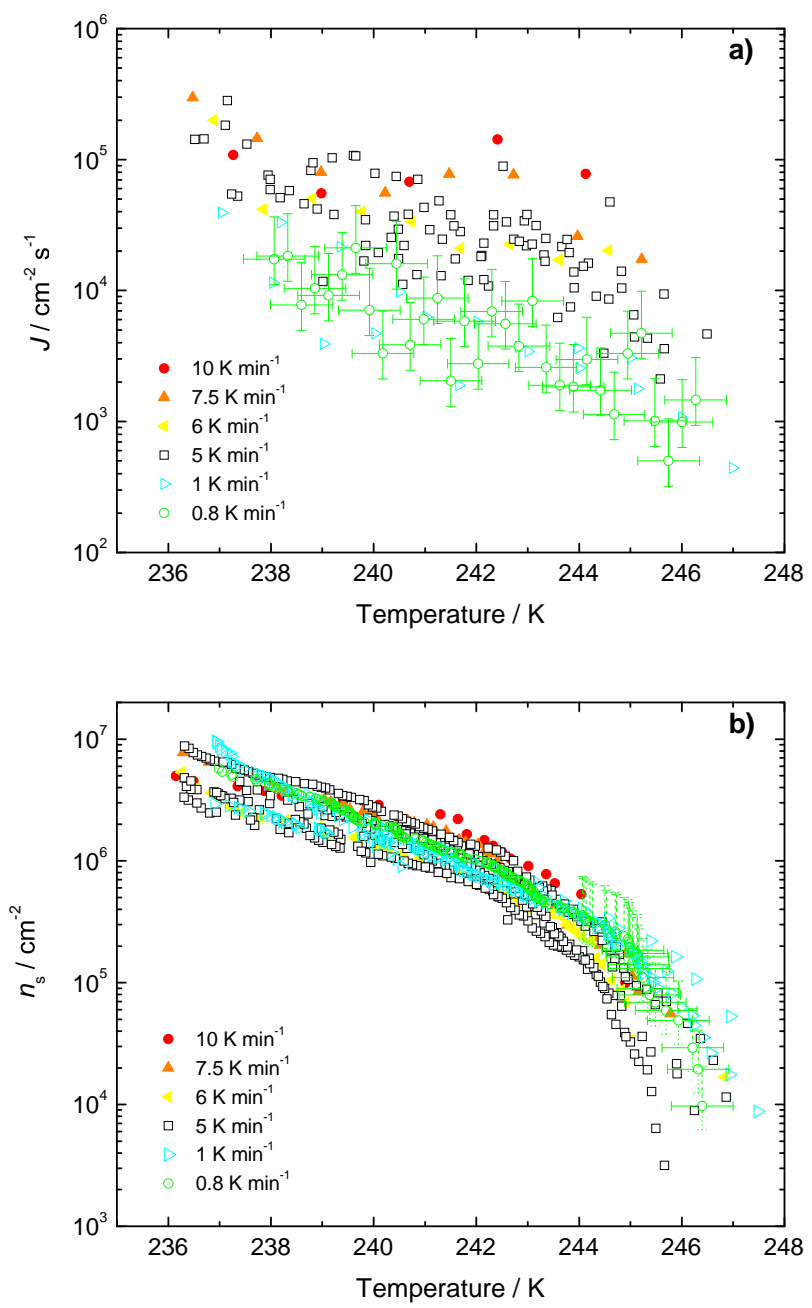

Fig. 6. (a) $J(T)$ as a function of cooling rate for droplets with concentrations between $0.007 \mathrm{wt} \%$ and $0.15 \mathrm{wt} \%$ in the $10-20 \mu \mathrm{m}$ size bin (runs 1a-6a, 12a-17a, 1b-2b and 17b). For clarity, error bars are only shown for run 13a. The uncertainties in $J(T)$ were calculated using the uncertainties in surface area, based on the uncertainty in droplet volume combined with the uncertainty in the specific surface area of illite. (b) $n_{S}(T)$ as a function of cooling rate for the same data as in panel a. For clarity, error bars are only shown for a few points in run $13 \mathrm{a}$. The uncertainties in $n_{S}(T)$ were also calculated using the uncertainties in surface area.

The surface area of illite in the large, low wt \% droplets shown in Fig. 5b ranged from $4.6 \times 10^{-6} \mathrm{~cm}^{2}$ to $7.2 \times$ $10^{-5} \mathrm{~cm}^{2}$. This is comparable to the surface area in the more concentrated droplets (run 10 and 11: $1.2 \times 10^{-5}$ $5.1 \times 10^{-5} \mathrm{~cm}^{2}$; see Table 3 ). In contrast, the surface area of illite in the low wt $\%, 10-20 \mu \mathrm{m}$ droplets was only $1.4 \times 10^{-6} \mathrm{~cm}^{2}$. Hence, droplets containing low surface areas of illite were found to exhibit no cooling rate dependence in their freezing behaviour but droplets containing higher surface areas (due to either higher concentrations or larger volumes) did appear to exhibit time dependence. 


\subsection{A high and low surface area regime}

As shown in Sects. 4.1 and 4.2, the freezing behaviour of droplets containing NX illite appears to depend on the total amount of material present in the droplets. Firstly, when low surface areas of NX illite were present in droplets freezing was cooling rate independent and the median freezing temperature clearly scaled with surface area. Secondly, when higher surface areas of NX illite were present freezing was cooling rate dependent and the median freezing temperature no longer depended on surface area in a simple way.

For simplicity, in this study we split the data into two distinct regimes: a high and a low surface area regime. For practical purposes we define an upper limit to the low surface regime as $2 \times 10^{-6} \mathrm{~cm}^{2}$, based on the point in Fig. 4 at which the surface area dependence begins to break down (note, run $6 \mathrm{a}$ is included in the low surface area regime, $s=2.02 \times 10^{-6} \mathrm{~cm}^{2}$ ). Assuming atmospheric dust particles are agglomerates of smaller particles with a similar surface area per unit mass to $\mathrm{NX}$ illite (i.e. $104 \mathrm{~m}^{2} \mathrm{~g}^{-1}$ ) then this threshold surface area would correspond to a particle diameter of $\sim 1 \mu \mathrm{m}$.

As the amount of material in a droplet increases, the probability of rare particles with distinct nucleation properties being present increases. It appears that NX illite contains a rare particle/nucleation site type which dominates the freezing process when the overall surface area is greater than $\sim 2 \times 10^{-6} \mathrm{~cm}^{2}$ per droplet. Taking the mean diameter based on the BET surface area $(20 \mathrm{~nm}$ assuming spherical particles), approximately 1 in $10^{5} \mathrm{NX}$ illite particles would be the rare particle type. Ice nucleation by this rare nucleation site would appear to have different time dependent properties compared to the bulk of the nucleation sites, which dominate nucleation for surface areas $\leq 2 \times 10^{-6} \mathrm{~cm}^{2}$ per droplet. At present, we do not know what material the rare nucleation site is associated with and if it is present in atmospheric samples or specific to NX illite.

It is also not clear what is causing the more complex surface area dependence in the high surface area regime. One possible explanation could be based on the fact that most of the droplets in the high surface area regime contained high concentrations of NX illite. It may be possible these high wt \% droplets were not stable; as the concentration of clay-in-water suspensions is increased, flocculation and settling out of material can occur; hence, results from concentrated clay-in-water suspensions should be treated with caution. This work highlights the need to use a range of cooling rates and IN concentrations when performing these types of experiments, in order to be able to quantify the ice-nucleating ability of a particular material in an atmospherically relevant manner.

In both the singular and stochastic hypotheses it is assumed that nucleation is surface area dependent, so only the low surface area regime can be analysed using these models. The remainder of this paper will focus on droplets con- taining $\leq 2 \times 10^{-6} \mathrm{~cm}^{2}$ of NX illite. However, further work should be done to identify and quantify ice nucleation by the rarer particle types, since agglomerates larger than $\sim 1 \mu \mathrm{m}$ (i.e. with surface areas $>2 \times 10^{-6} \mathrm{~cm}^{2}$ ) may contain this rare nucleation site.

\subsection{The single component stochastic model versus the singular model}

The low surface area data is now analysed according to both the single component stochastic and singular models in order to test which model provides a more accurate description of nucleation by NX illite. For the singular model, $n_{s}(T)$ was determined by rearranging Eq. (4):

$n_{s}(T)=\frac{-\ln \left(1-f_{\text {ice }}(T)\right)}{s}$

where $f_{\text {ice }}(T)$ is the cumulative fraction of frozen droplets. Similarly, for the stochastic model Eq. (7) was rearranged to obtain $J(T)$ values:

$J(T)=\frac{-\ln \left(1-n_{\text {ice }} / n\right)}{s . \Delta t}$

In this case, $J(T)$ was determined for time increments, $\Delta t$, over which the change in temperature due to cooling was small. Then, $n_{\text {ice }}$ is the number of droplets which froze heterogeneously in $\Delta t$ and $n$ is the number of liquid droplets at the beginning of the time interval. Time increments were chosen to maximise the number of $J(T)$ values obtained, but were also chosen so that there was at least one freezing event within that time increment as well as in the following or preceding time increment.

Figure 6 shows $n_{s}(T)$ and $J(T)$ for the droplets containing $s \leq 2 \times 10^{-6} \mathrm{~cm}^{2}$ (runs 1a-6a, 12a-17a, 1b-2b and 17b, see Tables 2 and 3 ) and for temperatures greater than the homogenous freezing limit. The homogenous freezing limit for each run was taken to be the temperature by which $10 \%$ of a population of pure water droplets would have frozen, for the same volume and cooling rate (determined from the parameterisation in Murray et al. (2010)).

Inspection of Fig. 6a reveals that $J(T)$ varies systematically with the cooling rate, rather than falling on a single line. At $242 \mathrm{~K}, J$ increases by two orders of magnitude on increasing the cooling rate by a factor of 10 . In a previous study, it was found that ice nucleation by kaolinite with a similar range of cooling rates could be described by a single temperature dependent nucleation rate coefficient, consistent with the single component stochastic model (Murray et al., 2011b). Unlike kaolinite, the poor fit in Fig. 6a clearly shows that the single component stochastic model cannot describe ice nucleation by NX illite (with $s \leq 2 \times 10^{-6} \mathrm{~cm}^{2}$ droplet $^{-1}$ ).

However, this data can be described by a single temperature dependent value of $n_{s}$ (Fig. 6b). At $242 \mathrm{~K}, n_{s}$ varies by only about a factor of three in a non-systematic way for a 

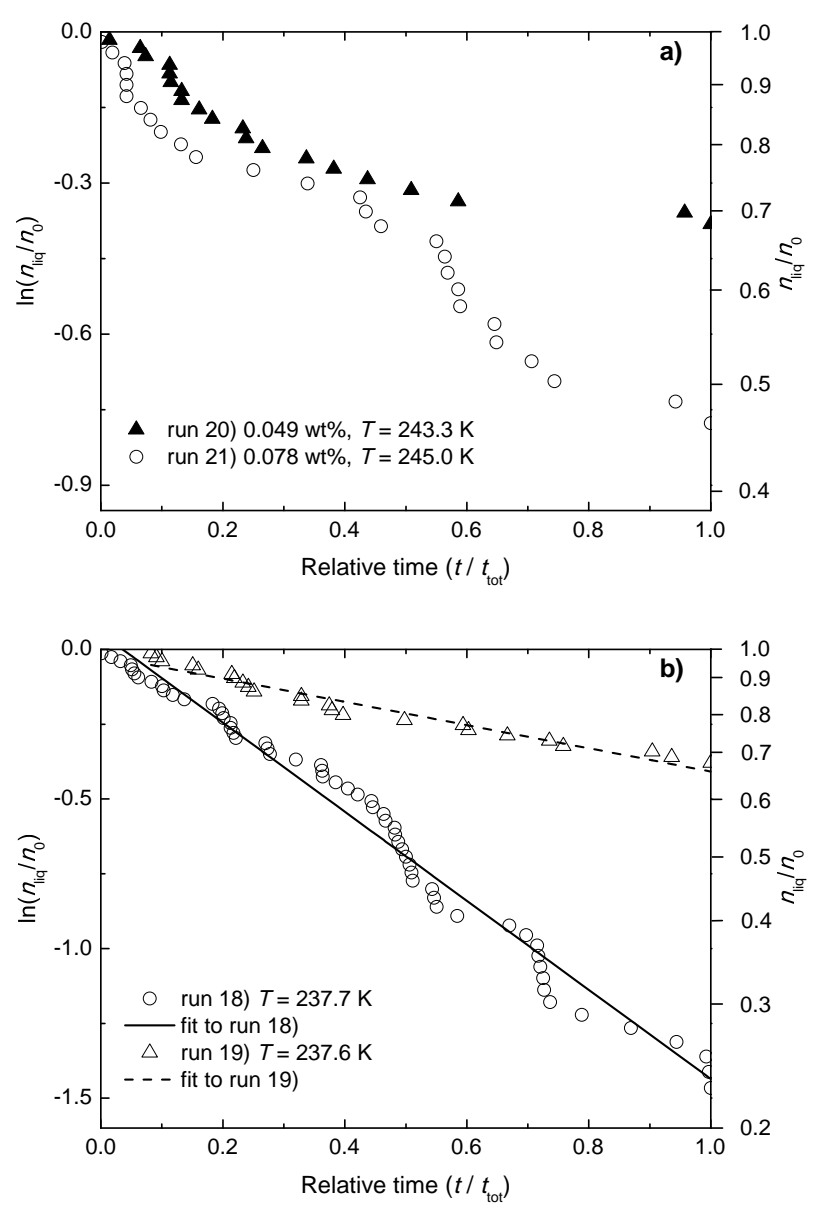

Fig. 7. (a) The decrease in the fraction of droplets which were liquid $\left(n_{\text {liq }} / n_{0}=1-n_{\text {ice }} / n_{0}\right)$ with relative time at constant temperature, where $n_{0}$ is defined as the number of liquid droplets at the beginning of the isothermal experiment (i.e. excluding any droplets which froze during cooling to the isothermal temperature). The relative time is defined as $t / t_{\text {tot }}$ where $t_{\text {tot }}$ is the total time the droplets were held at constant temperature. Two heterogeneous isothermal experiments are shown for two different temperatures (uncertainty is $\pm 0.6 \mathrm{~K})$ and concentrations. The numbering in the key corresponds to the information in Table 3. For runs 20 and $21, t_{\text {tot }}=646 \mathrm{~s}$ and $853 \mathrm{~s}$, respectively. (b) Two homogeneous experiments for comparison. The straight lines are linear fits to the homogeneous data. For runs 18 and $19, t_{\text {tot }}=2727 \mathrm{~s}$ and $222 \mathrm{~s}$, respectively.

factor of 10 change in cooling rate and this variation is within experimental uncertainties. Hence, Fig. 6 shows that droplet freezing on NX illite in the low surface area regime can be described by the singular model. This suggests that the time dependence of nucleation over this range of cooling rates is negligible.

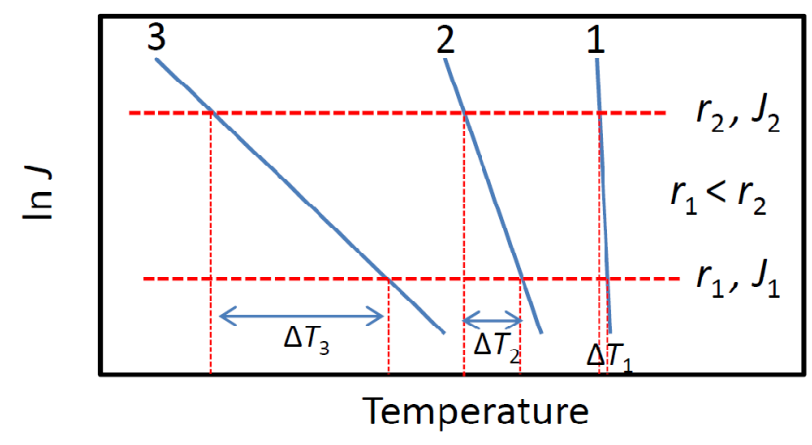

Fig. 8. Illustration of how the slope $\ln J / T$ controls the dependence of freezing temperature on cooling rate. In order to maintain the same probability of freezing on increasing the cooling rate (and decreasing the time for nucleation) it is necessary to go to a lower temperature and correspondingly to larger nucleation rate coefficients. If the slope is very steep (line 1 ) then increasing cooling rate from $r_{1}$ to $r_{2}$ results in a very small decrease in observed freezing temperature $\left(\Delta T_{1}\right)$. As the slope decreases in steepness (line 2 and 3 ) the dependence of $\Delta T$ on cooling rate increases. In the singular model of ice nucleation $\mathrm{d} \ln J / \mathrm{d} T \rightarrow \infty$ and nucleation temperature is time independent.

\subsection{Isothermal experiments in the low surface area regime}

Additional experiments were also performed in which droplets were cooled and then held at a single temperature for a period of time, before cooling was resumed. The fraction of droplets which were liquid ( $n_{\text {liq }}=1-n_{\text {ice }} / n_{0}$; where $n_{0}$ is the number of liquid droplets at the beginning of the isothermal segment) is shown as a function of time in Fig. 7a for two isothermal experiments. This clearly shows that nucleation continues with time during these experiments, which is inconsistent with the singular model. These experiments were both performed using droplets containing low surface areas of NX illite $\left(<1 \times 10^{-6} \mathrm{~cm}^{2}\right.$, see Table 4), for which the singular model, which is time independent, could describe the results from the cooling ramp experiments. This apparent discrepancy between cooling ramp and isothermal experiments will be investigated in the next section.

Assuming nucleation is stochastic and that there is a single particle (or nucleation site) type, Eq. (7) predicts an exponential decay of liquid droplets with time during isothermal experiments; hence, $\ln \left(1-n_{\text {ice }} / n_{0}\right)$ versus $t$ should be linear with a slope of $s J$. However, neither run 20 nor run 21 show linear behaviour. For comparison, Fig. 7b shows two isothermal homogenous experiments (i.e. pure water droplets with no added inclusions), for which $\ln \left(1-n_{\text {ice }} / n_{0}\right)$ versus $t$ is approximately linear, as expected, with a slope of $J V$. The shorter time scale variations in slope could be caused by temperature fluctuations or may just be a statistical phenomenon due to the relatively low number of droplets present. 

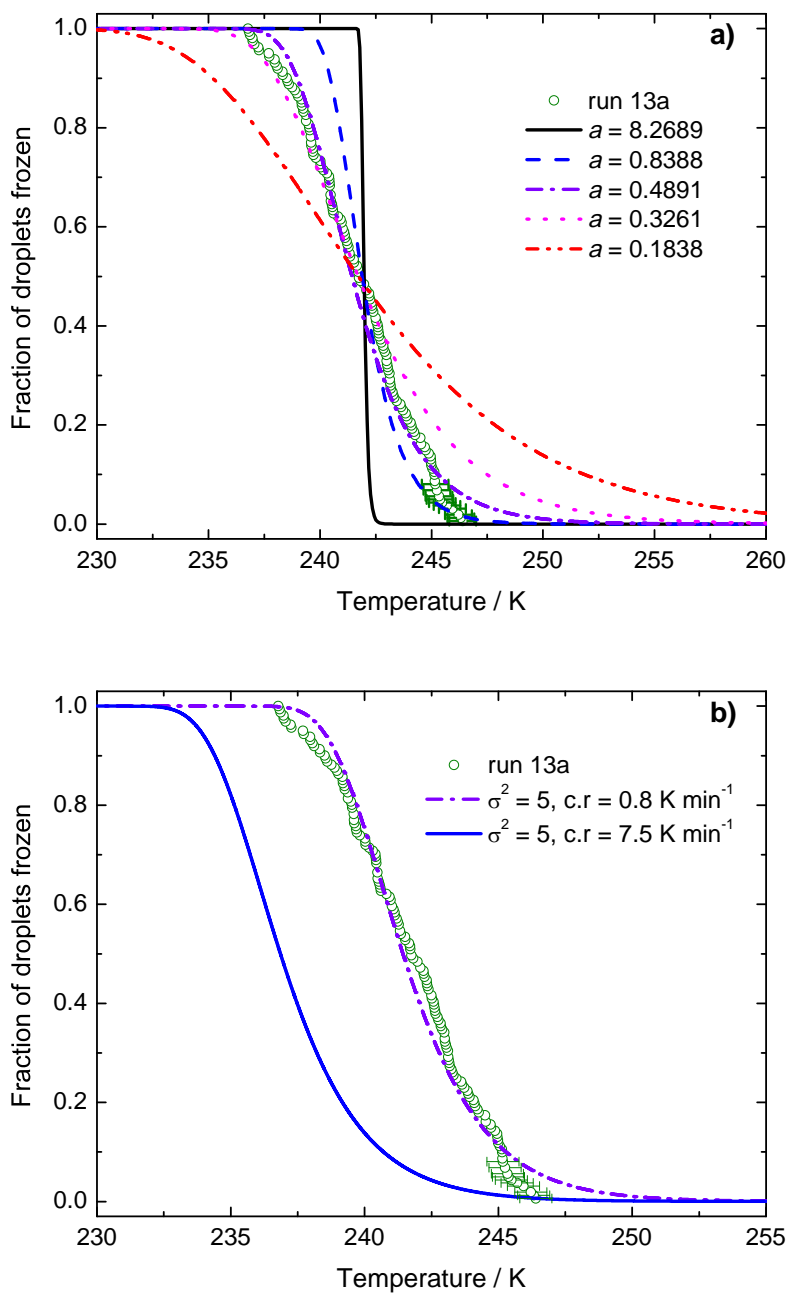

Fig. 9. Theoretical $f_{\text {ice }}(T)$ curves for droplets containing internally mixed nucleation sites of varying ice-nucleating ability, which were characterised by $\ln \left(J_{i}(T)\right)=-a T+b_{i}$. Also shown is run 13a, for comparison (limited $T$ uncertainties are shown, for clarity). (a) Theoretical curves are shown for different values of $a$, where $\sigma_{b}$ was kept constant (see text). $\mu_{b}$ was varied to best fit the experimental $f_{\text {ice }}(T)$ curve. The following values of $\mu_{b}$ were used: $\mu_{b}=$ 2000, 200, 114.7, 75 and 40 for $a=8.2689,0.8388,0.4891,0.3261$ and 0.1838 , respectively $\left(\sigma_{b}^{2}=5\right)$. All theoretical $f_{\text {ice }}(T)$ curves were calculated for a cooling rate of $0.8 \mathrm{~K} \mathrm{~min}^{-1}$. (b) The affect of changing the cooling rate is shown using curves calculated with a value of $a=0.4891$. This shows that the internally mixed model is inconsistent with the experimentally observed lack of cooling rate dependence.

For our heterogeneous isothermal experiments, there also appears to be shorter timescale fluctuations in slope, but in general the slope is steeper in the initial section. This indicates that some droplets had a greater probability of freezing than others. One explanation is that different droplets may not have contained the same surface area, due to an inhomogeneous distribution of particles or particle sizes be- tween droplets, which could have occurred during nebulisation. However, the surface area of NX illite in the droplets which nucleated in the first half of run 20 would have needed to be about seven times larger than the surface area in the droplets which nucleated in the second half if only one type of nucleation site was present, which seems unlikely. In addition, this did not appear to be the case when we applied the same experimental technique to ice nucleation by kaolinite (Murray et al., 2011b). Therefore, the more likely explanation for the non-single-exponential decay of liquid droplets containing illite is that there is a distribution of nucleation sites of varying ability between the droplets.

\subsection{Describing ice nucleation by NX illite with a multiple component stochastic model: reconciling cooling rate independence with time dependence at constant temperature}

The experimental data presented above for droplets containing surface areas of $\leq 2 \times 10^{-6} \mathrm{~cm}^{2}$ per droplet show that nucleation occurred over a wide range of temperatures and was independent of cooling rates between 0.8 and $10.3 \mathrm{~K} \mathrm{~min}^{-1}$. The cooling ramp data can therefore be described by the singular model; however, measurements of nucleation at constant temperature are inconsistent with this time independent model. In this section, we will show that these apparently contradictory measurements can be reconciled using a multiple component stochastic model.

The multiple component stochastic model was discussed in detail by Murray et al. (2011b) and describes systems in which there is more than one nucleating species or type of nucleation site. Each nucleation site can be described by a single temperature dependent nucleation rate coefficient and the total absolute rate of freezing is a function of the distribution of nucleation sites. Previously, the distribution of ice nucleating ability of particles has been described with a distribution of contact angles in the context of classical nucleation theory (Marcolli et al., 2007; Stoyanova et al., 1994). Very recently, Niedermeier et al. (2011) presented a conceptual 'soccer ball' model with the aim of reconciling stochastic and singular behaviour in ice nucleation. Their model treats particles as having a surface containing a number of regions of varying ice nucleation ability. The nucleation efficiency on each surface region was described with a contact angle and the nucleation probability then determined using classical nucleation theory.

In this study, a simple functional form for the temperature dependent rate coefficient for each nucleation site $J_{i}(T)$ was applied:

$\ln \left(J_{i}(T)\right)=-a_{i} T+b_{i}$

where $a$ and $b$ are adjustable parameters. Homogeneous and heterogeneous nucleation rate coefficients have been parameterised in this form for relatively narrow ranges of temperatures in the past and it is therefore thought to be a reasonable 
simplification (Murray et al., 2011b). This description was chosen rather than a contact angle based approach because it is more flexible as it allows control over both the magnitude of $J$ and its temperature dependence. The parameter $a$ defines the slope $\operatorname{d} \ln J / \mathrm{d} T$ and we will show that this term is key for reconciling cooling rate independence with a time dependent model. However, nucleation rates based on CNT will also be considered briefly at the end of this section.

The dependence of freezing temperature on $\mathrm{d} \ln J / \mathrm{d} T$ and cooling rate is qualitatively illustrated in Fig. 8. Three hypothetical lines are shown with increasing steepness (lines $1-3)$. On increasing the cooling rate $(r)$, a lower temperature will be required to maintain the fraction of droplets frozen at $50 \%$, since less time will be available for freezing at any one temperature. This is clear from Eq. (7); in order to maintain $f_{\text {ice }}$ at 0.5 for faster cooling rates (smaller $t$ ), $J$ needs to be larger for constant surface area. Larger $J$ values are obtained at lower temperatures; hence the slope $\operatorname{dn} J / \mathrm{d} T$ determines the change in observed freezing temperature when varying cooling rate, but one would still expect nucleation at constant temperature given the rate coefficient has units of time.

A distribution of nucleation sites was modelled by introducing a distribution of $b$ values for a fixed value of $a$, where a larger value of $b_{i}$ results in a more effective nucleation site. For simplicity, the occurrence probability of a nucleation site characterized by $b_{i}\left(P_{b, i}\right)$ was described by a normal probability function, with a mean $\mu_{b}$ and standard deviation $\sigma_{b}$.

For this study we will explore two scenarios; in the first we will assume that every droplet contains the same distribution of nucleation sites of different types (internally mixed) and in the second we will assume that the nucleation sites of different types are distributed throughout the droplets (externally mixed). These scenarios will be used to try and reproduce the freezing behaviour of droplets containing NX illite in the low surface regime, both in the cooling ramp and isothermal experiments. Our aim in this fitting process is to reconcile the lack of cooling rate dependence with continued ice nucleation at constant temperature.

Internally mixed case. Assuming that each water droplet contains all nucleation site types (i.e. droplets are internally mixed), then the change in number of ice particles $\left(\Delta n_{\text {ice }}\right)$ in a time increment $(\Delta t)$ is:

$\Delta n_{\text {ice }}=n_{\text {liq }}\left(1-\exp \left(\sum_{i}-J_{i}(T) s_{i} \Delta t\right)\right)$

where $s_{i}$ is the surface area of the nucleation site $(i)$ $\left(s_{i}=s P_{b, i}\right.$, where $s$ is the overall surface area per droplet) and $n_{\mathrm{liq}}$ is the number of liquid droplets at the beginning of the time increment.

Several theoretical $f_{\text {ice }}(T)$ curves are shown in Fig. 9a for different values of $a$, where $\sigma_{b}$ was kept constant but $\mu_{b}$ was varied to try and best reproduce the experimental $f_{\text {ice }}(T)$ curve (run 13a; $0.8 \mathrm{~K} \mathrm{~min}^{-1}$ ). It is clear that the $f_{\text {ice }}(T)$ curves become steeper as $a$ is increased. The experimental

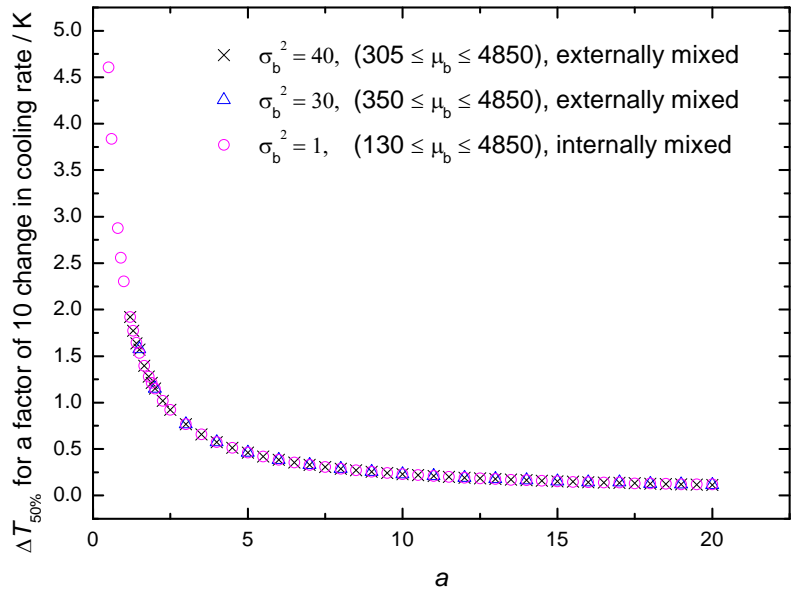

Fig. 10. The cooling rate dependence of freezing temperature on the parameter $a(\mathrm{~d} \ln J / \mathrm{d} T)$. Cooling rate dependence is indicated by $\Delta T_{50} \%$, which is the change in median freezing temperature on a factor of 10 change in cooling rate. The dependence is insensitive to the choice of $\sigma_{b}$ and $\mu$. The values shown in this graph were calculated for both externally and internally mixed droplets.

data is best reproduced when $a$ is 0.4891 and $\mu_{b}=114.7$ (determined using a least squared fit) and $\sigma_{b}^{2}=5$.

Earlier in the paper it was shown that there was no discernable change in experimental $f_{\text {ice }}(T)$ on varying the cooling rate by about a factor of 10 (see Fig. 5a). However, Fig. 9b shows that increasing the cooling rate from $0.8 \mathrm{~K} \mathrm{~min}^{-1}$ to $7.5 \mathrm{~K} \mathrm{~min}^{-1}$ noticeably shifts the theoretical $f_{\text {ice }}(T)$ curve to much lower temperatures, which is clearly inconsistent with the experimental data.

The cooling rate dependence on $a$ is further illustrated in Fig. 10, which plots $\Delta T_{50 \%}$ (change in median freezing temperature) for a factor of 10 change in cooling rate as a function of $a$. The value of $a \approx 0.5$ required in order to reproduce the experimental fraction frozen curve corresponds to a $\Delta T_{50 \%}$ of $4.6 \mathrm{~K}$ for a factor of 10 change in cooling rate (see Fig. 9). To obtain a negligible cooling rate dependence using internally mixed droplets, $a$ would need to be greater than $\sim 8$ (based on our experimental reproducibility of $0.3 \mathrm{~K}$ ), but the corresponding $f_{\text {ice }}(T)$ curve would be much steeper than the experimental data. Hence, the internally mixed case, where every droplet contains the same distribution of nuclei types, is inconsistent with the experimental data obtained during the cooling ramp experiments.

Compelling evidence against an internally mixed case is also provided by the isothermal data. For internally mixed droplets, each droplet must have the same freezing probability and therefore one would expect a single exponential decay. This is clearly inconsistent with the experimental data obtained at a constant temperature shown in Fig. 7 a. 


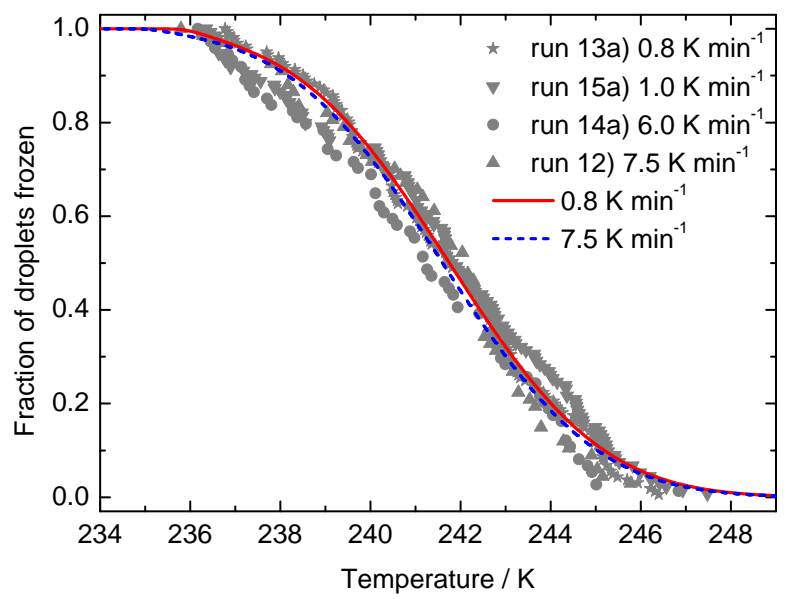

Fig. 11. Theoretical $f_{\text {ice }}(T)$ curves for droplets containing externally mixed nucleation sites with a normal distribution of icenucleating abilities, which were characterised by $\ln \left(J_{i}(T)\right)=-a T+$ $b_{i}$. The theoretical $f_{\text {ice }}$ curve for a cooling rate of $0.8 \mathrm{~K} \mathrm{~min}^{-1}$ was fitted to the experimental run 13a, using a least squared technique to minimise $\mu_{b}$ and $\sigma_{b}^{2}$ where $a$ was fixed at 15 . Using the same fit parameters $\left(\mu_{b}=3637.7\right.$ and $\left.\sigma_{b}^{2}=40.2\right)$ we then calculated the $f_{\text {ice }}$ curve for a cooling rate of $7.5 \mathrm{~K} \mathrm{~min}^{-1}$ which falls well within the spread of the experimental data. This shows that the multiple component stochastic model with a large value of $a$ can reproduce the cooling rate independence.

Externally mixed case. In this case, each droplet contains a different mixture of nucleation sites; hence some droplets contain much more efficient nucleation sites than others. For simplicity, we assume that the most effective nucleation site in each droplet causes freezing; this is equivalent to only one type of nucleation site being present in each droplet. For this case:

$\Delta n_{\text {ice }}=\sum_{i} n_{i}\left(1-\exp \left(-J_{i}(T) s . \Delta t\right)\right)$

where $n_{i}$ is the number of liquid droplets containing nucleation site $i$ at the beginning of a time step $\left(\right.$ at $0^{\circ} \mathrm{C}, n_{i}=$ $n P_{b, i}$, where $n$ is the total number of droplets). Two theoretical $f_{\text {ice }}(T)$ curves based on the externally mixed multiple component stochastic model are shown in Fig. 11. The first theoretical $f_{\text {ice }}$ curve was fitted to the experimental run 13a $\left(0.8 \mathrm{~K} \mathrm{~min}^{-1}\right)$, using a least squared minimisation routine to fit $\mu_{b}$ and $\sigma_{b}^{2}$ where $a$ was fixed at 15 . Using the same fit parameters $\left(\mu_{b}=3637.7\right.$ and $\left.\sigma_{b}^{2}=40.2\right)$ we then calculated the $f_{\text {ice }}$ curve for a cooling rate of $7.5 \mathrm{~K} \mathrm{~min}^{-1}$. Since $a$ is relatively large the $f_{\text {ice }}$ curve only shifts by $\sim 0.15 \mathrm{~K}$ (see Fig. 10), which is too small to detect experimentally in the current system. Hence, the time dependent multiple component stochastic model is shown to be consistent with cooling rate independence.

It should be noted that the fits shown in Fig. 11 are not unique, and the experimental curves could be fitted with

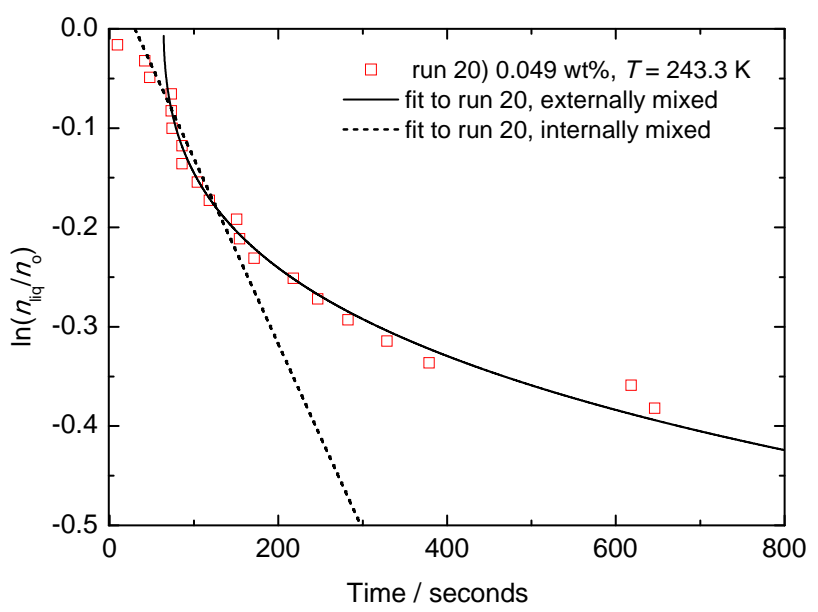

Fig. 12. Model fits to the experimental decrease in the fraction of droplets which were liquid $\left(n_{\text {liq }} / n_{o}=1-n_{\text {ice }} / n_{o}\right)$ with time at constant temperature for run 20 . The model lines were calculated by assuming that the droplets contained a different mixture of nucleation sites (externally and internally mixed) which was described by a normal distribution. The parameters used were as follows: for the externally mixed model $a=15, \mu_{b}=3659, \sigma_{b}^{2}=4.1$ and for the internally mixed model, $a=15, \mu_{b}=3617.5, \sigma_{b}^{2}=10.1$. We also fitted an offset to the time to take into account any delays in temperature equilibration of the droplets with the stage, hence the model fits start at positive times.

other combinations of variables, including larger values of $a$ (resulting in a smaller $\Delta T_{50 \%}$ ). In order to obtain a full numerical fit to the data using this model, $a$ must be fixed using an experimentally determined value for $\Delta T_{50 \%}$. Unfortunately, the temperature resolution in these experiments was insufficient to determine $a$ for NX illite.

The results are compared for the externally and internally mixed models to an isothermal data set (run 20) in Fig. 12. The externally mixed model can reproduce the non-singleexponential decay of liquid droplets exhibited during the experiment. Both theoretical curves shown in Fig. 12 were calculated using $a=15$, to be consistent with Fig. 10. Again, it should be noted that these are not unique fits and the experimental curves could be fitted with other combinations of variables. Nevertheless, the externally mixed model is consistent with the experimental data.

Figure 13 shows fits to a range of fraction frozen curves for experiments with a range of NX illite surface areas. In these fits $a$ was held constant at 15 , while $\mu_{b}$ and $\sigma_{b}^{2}$ were allowed to vary. The resulting distributions of $b$ are shown in Fig. 14 and it is clear that as the surface area per droplet increases the distribution mean $\left(\mu_{b}\right)$ shifts to more efficient $b$ values and the distribution decreases in width. This is consistent with the idea that as the amount of material per droplet increases, there is greater chance of finding rarer but more effective IN in any one droplet. Further work is needed to 


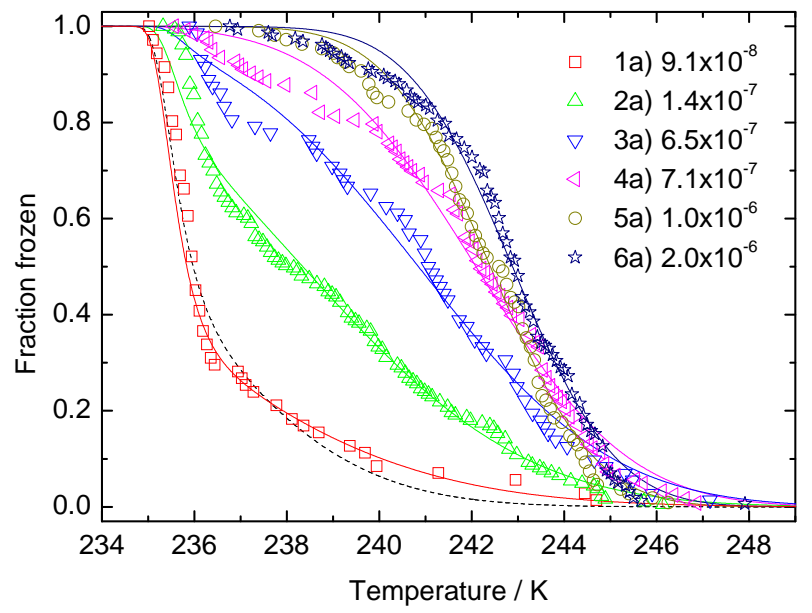

Fig. 13. Model fits to a range of experimental fraction frozen curves using the externally mixed multiple component stochastic model. The experimental data was all for $5 \mathrm{~K} \mathrm{~min}^{-1}$ cooling rates for a range of NX illite surface areas (given in the key with units $\mathrm{cm}^{2}$ ). $a$ was set to 15 and a least squared fitting routine was used to obtain the best fit by varying $\mu_{b}$ and $\sigma_{b}^{2}$. The corresponding distributions, $P_{b, i}$, of the parameter $b$ are shown in Fig. 14. Two fits to run1a are shown (red). The dotted line is a fit to the whole data set, while the red line is a fit to only the data points above $237 \mathrm{~K}$. The dotted line provides a better fit to the whole data set, however, the solid red line clearly provides a better fit to the portion of the data dominated by heterogeneous freezing and it is this distribution plotted in Fig. 14.

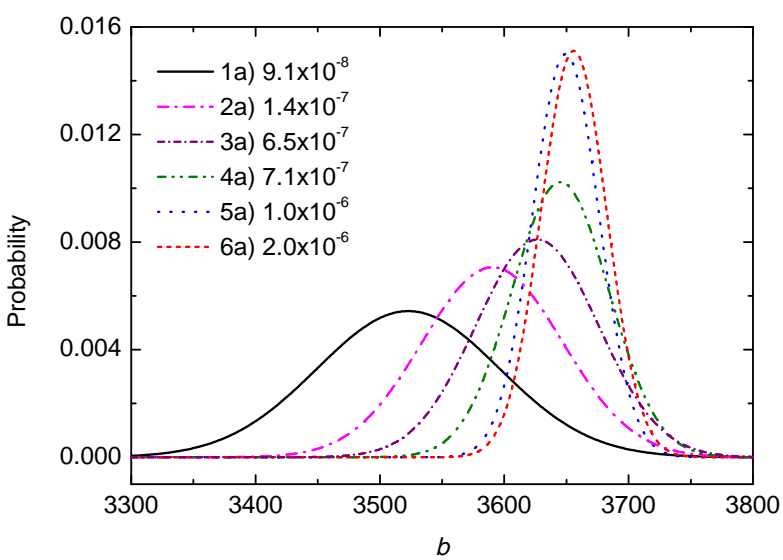

Fig. 14. Fitted normal distributions of $b$ for the fraction frozen curves in Fig. 13. The values in the key are the median surface area per droplet of NX illite in $\mathrm{cm}^{2}$.

relate this information to the distribution of ice nucleating abilities of the individual NX illite particles.

In summary, freezing of droplets in the cooling ramp experiments can be described assuming that there is a distribution of types of nucleation sites between droplets, but where nucleation on each site is governed by a stochastic equa-
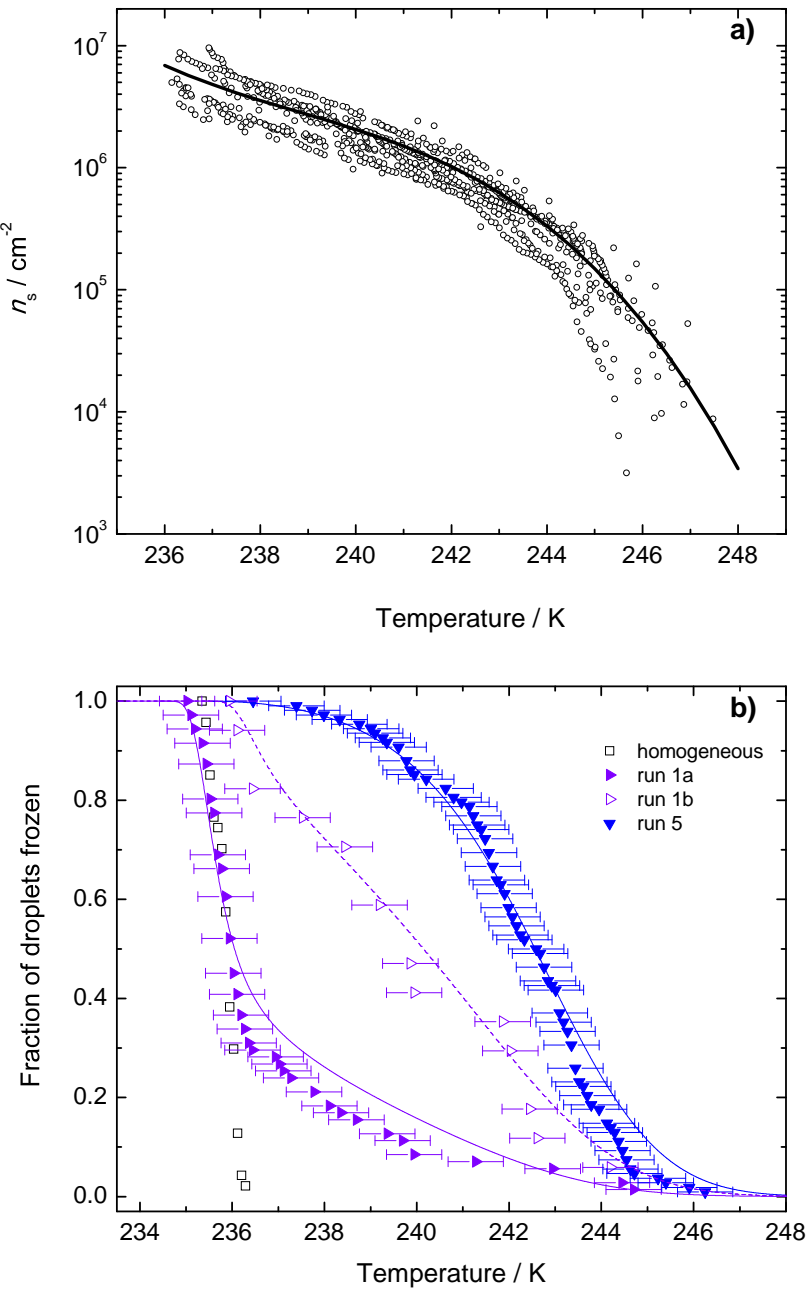

Fig. 15. (a) Fit to $\ln \left(n_{s}(\mathrm{~T})\right)$ for runs with a median surface area of $\leq 2 \times 10^{-6} \mathrm{~cm}^{2}$ (runs 1a-6a, 12a-17a, 1b-2b and 17b). (b) Fraction of droplets frozen as a function of temperature for two illite concentrations. The experimental data is compared with our parameterisation (lines, see text).

tion (i.e. the multiple component stochastic model). In addition, the nucleation functions associated with these nucleation sites needed to be steep in order to reproduce the observed cooling rate independence. The isothermal data could also be fitted using these assumptions. Hence, the multiple component stochastic model is able to reconcile cooling rate independence with nucleation at constant temperature.

Classical nucleation theory based model. This paragraph will briefly consider the implementation of CNT into the multiple component stochastic model. CNT based on Marcolli et al. (2007) (and all references therein) was used to describe $J(T)$. The distribution of contact angles across the droplet population was determined as outlined above in Eq. (17) with $n_{i}=n P_{\theta i}$, where $\theta$ is the contact angle. Using this model resulted in a temperature shift of $\sim 0.6 \mathrm{~K}$ on a 
Table 5. Parameters $A, B, C$, and $D$ for the parameterisation of $n_{S}(T)$ or $k(T)$ for the immersion freezing of water droplets containing illite in the low surface area regime.

\begin{tabular}{lrr}
\hline Parameter & Value & Uncertainty \\
\hline$A$ & $6.53043 \times 10^{4}$ & $1.01157 \times 10^{4}$ \\
$B$ & $-8.2153088 \times 10^{2}$ & $1.25733363 \times 10^{2}$ \\
$C$ & 3.446885376 & 0.520901018 \\
$D$ & $-4.822268 \times 10^{-3}$ & $0.719300 \times 10^{-3}$ \\
\hline
\end{tabular}

factor of 10 change in cooling rate, which is inconsistent with our measurements.

\section{Parameterisation of nucleation by NX illite in the immersion mode for use in models}

While we have shown that the model that can best describe ice nucleation by NX illite is the multiple component stochastic model, it has a number of disadvantages for use in cloud models. Firstly, while we have been able to reconcile cooling rate independence and time dependence at constant temperature, we have not been able to produce a full fit to the data since we cannot determine a unique value of $a$. Secondly, in many cloud types, particularly those with rapid cooling rates, inclusion of the time dependence in the parameterisation of ice nucleation may not be important. When modelling these clouds the time independent singular description may be both adequate and more computationally efficient.

In Fig. 15a we show a fit to $\ln \left(n_{s}(T)\right)$ which was derived for the low surface area data $\left(<2 \times 10^{-6} \mathrm{~cm}^{2}\right.$ per droplet $)$. Only data obtained during constant cooling experiments can be represented using the singular model, with freezing at constant temperature inconsistent with this model. A thirdorder polynomial was found to adequately describe this data:

$n_{s}(T)=\exp \left(A+B T+C T^{2}+D T^{3}\right)$

for $236.2 \mathrm{~K} \leq T \leq 247.5 \mathrm{~K}$. The differential surface site density $(k(T))$ can also be determined using these fitted parameters:

$k(T)=\left(B+2 C T+3 D T^{2}\right) \exp \left(A+B T+C T^{2}+D T^{3}\right)$

The determined values of $A, B, C$ and $D$ are listed in Table 5. It should be noted that this parameterisation should not be used for temperatures below $236.2 \mathrm{~K}$, due to the nature of the third-order polynomial fit. In addition, since this parameterisation is based on experimental data with surface areas $\leq 2 \times 10^{-6} \mathrm{~cm}^{2}$, it may under predict ice nucleation above $\sim 247 \mathrm{~K}$.
The self consistency of this parameterisation is shown in Fig. 15b, which compares three experimental runs with modelled $f_{\text {ice }}(T)$ curves. For droplets during a cooling ramp experiment undergoing heterogeneous freezing only, an expression for the change in number of frozen droplets, $\Delta n_{\text {ice }}$, per temperature interval, $\Delta T$, can be derived from Eq. (4) since $k(T)=\mathrm{d} n_{s}(T) / \mathrm{d} T$ (Connolly et al., 2009):

$\Delta n_{\text {ice }}=n_{\text {liq }}(1-\exp (-k(T) s . \Delta T))$

where $n_{\text {liq }}$ is the number of liquid droplets at the beginning of the temperature interval. This equation can be extended to include the rate of homogeneous freezing which becomes increasingly important below $237 \mathrm{~K}$ :

$\Delta n_{\text {ice }}=n_{\text {liq }}\left(1-\exp \left(-\left(k(T) s . \Delta T+J_{\text {hom }}(T) V . \Delta t\right)\right)\right.$

The quantities $\Delta T$ and $\Delta t$ are related by the cooling rate $r$, i.e. $\Delta T=r . \Delta t$ and the parameterisation for $J_{\mathrm{hom}}(T)$ is taken from Murray et al. (2010). The resulting model predictions in Fig. 15b are consistent with the experimental data.

Our parameterisation for $n_{s}$ and Eq. (21) are used to predict fraction frozen curves for droplets containing varying sizes of mineral dust inclusions (see Fig. 16). In order to determine the surface area of atmospheric particles it is important to take into account their morphology. Mineral dust particles are known to be aggregates of many smaller particles (Lieke et al., 2011; Kandler et al., 2007) and this means that they can have a much greater surface area than a smooth sphere of similar mass. The surface area was determined by assuming that atmospheric particles have the same surface area per unit mass as NX illite $\left(104 \mathrm{~m}^{2} \mathrm{~g}^{-1}\right)$ and a density of $2.7 \mathrm{~g} \mathrm{~cm}^{-3}$. According to these assumptions a $0.5 \mu \mathrm{m}$ diameter aggregate would have a surface area of $1.8 \times 10^{-7} \mathrm{~cm}^{2}$, whereas an equivalent smooth sphere would have a surface area 23 times smaller.

The dependence of freezing temperatures on the size of particles is shown to be very strong in Fig. 16, which illustrates that larger particles are more likely to catalyse freezing. This is consistent with DeMott et al. (2010) who argue that particles larger than $0.5 \mu \mathrm{m}$ dominate heterogeneous ice nucleation in the atmosphere. In addition, we compare our parameterisation (Eqs. 18-21) to that of Diehl and Wurzler (2004) which is for pure illite. Since our sample contained $61 \%$ illite it is reasonable to make this comparison because, due to a larger number of particles estimated to be present in each of our droplets, every droplet was likely to contain illite. The freezing temperatures of dust according to our parameterisation are strongly size dependent, whereas Diehl and Wurzler's parameterisation is independent of particle size (or surface area). This suggests that Diehl and Wurzler's parameterisation over predicts the ice nucleating efficiency of many mineral dust particles and only represents the ice nucleating ability of a subset of the largest $(<1 \mu \mathrm{m})$ and most efficient atmospheric particles.

Another important point is raised on inspection of Figs. 15 and 16: homogeneous nucleation is predicted even though 


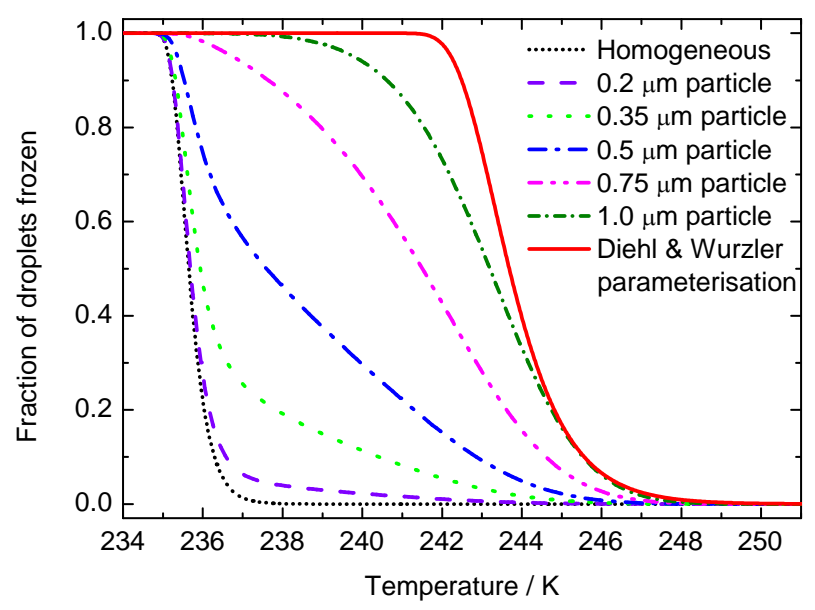

Fig. 16. Predicted fraction frozen curves for droplets containing mineral dust particles with a range of diameters. It is assumed that these particles are aggregates of smaller particles and have the same total surface area per mass as NX illite $\left(104 \mathrm{~m}^{2} \mathrm{~g}^{-1}\right)$ with a density of $2.7 \mathrm{~g} \mathrm{~cm}^{-3}$. The curves are calculated according to Eq. (21) for droplet diameters of $15 \mu \mathrm{m}$. We also show the result of Diehl and Wurzler's (2004) parameterisation for illite which is surface area independent.

the droplets contain solid particles. This shows that homogeneous nucleation can be more effective than heterogeneous nucleation under certain conditions. This behaviour was also observed during experiments investigating immersion mode freezing by kaolinite and was discussed in some detail previously (Murray et al., 2011b).

Equation (21) can also be extended to describe heterogeneous freezing by multiple $(i)$ nucleation site types. Nucleation by some materials, such as kaolinite, lend themselves to being described by a single component stochastic model (i.e. $J(T)$ ) (Murray et al., 2011b), whereas nucleation by other materials such as NX illite are more readily described using a singular description (i.e. $k(T)$ ). If particles of multiple species are dispersed evenly throughout a population of droplets, i.e. internally mixed, then the number of freezing events during cooling can be described using:

$\Delta n_{\text {ice }}=n_{\text {liq }}\left(1-\exp \left(-\left(\Sigma k_{i}(T) s_{i} \Delta T+\Sigma J_{i}(T) s_{i} \Delta t+J_{\text {hom }}(T) V \Delta t\right)\right)(22)\right.$

To test the validity of this expression we made up a suspension containing both $0.01 \mathrm{wt} \% \mathrm{NX}$ illite and $0.15 \mathrm{wt} \%$ kaolinite KGa- $1 \mathrm{~b}$. The experimental results and model curve based on Eq. (22) are illustrated in Fig. 17. The time dependent parameterisation for kaolinite from Murray et al. (2011b) was used together with the singular description for NX illite described above. The predicted curve is in agreement with the experimental data.

While the singular parameterisation for NX illite presented here is self consistent with the experimental cooling ramp data, it should be noted that extrapolation to much slower

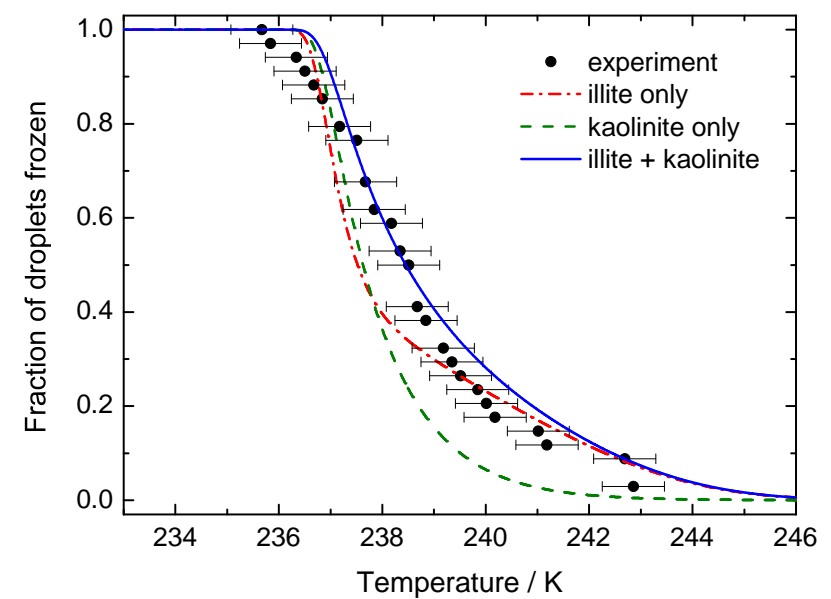

Fig. 17. Fraction of droplets frozen as a function of temperature for droplets containing an internal mixture of $0.01 \mathrm{wt} \% \mathrm{NX}$ illite and 0.15 wt $\%$ kaolinite. The blue line is our predicted $f_{\text {ice }}(T)$ curve based on Eq. (22) and using the parameterisations for ice nucleation by kaolinite (Murray et al., 2011b) and NX illite (Eq. 19). The predicted $f_{\text {ice }}(T)$ curves assuming only illite and only kaolinite were present are also shown. The experimental $f_{\text {ice }}(T)$ curve was produced using 34 droplets in the $10-20 \mu \mathrm{m}$ size range. The surface area of clay available in the median volume droplet $(V=$ $1.1 \times 10^{-9} \mathrm{~cm}^{3}$ ) was $s=1.39 \times 10^{-7} \mathrm{~cm}^{2}, 1.92 \times 10^{-7} \mathrm{~cm}^{2}$ for illite and kaolinite, respectively; the cooling rate was $10.0 \mathrm{~K} \mathrm{~min}^{-1}$.

cooling rates related to weaker in-cloud updraughts should be applied with caution. While our experiments are insensitive to cooling rate between 0.8 and $10 \mathrm{~K} \mathrm{~min}^{-1}$, we have also shown nucleation is time dependent and this may become important in weakly forced clouds.

\section{Summary and conclusions}

Heterogeneous nucleation by NX illite was found to occur over a range of temperatures, dominantly between $246 \mathrm{~K}$ and the homogeneous limit. The freezing behaviour of the droplets in our experiments could be split into two regimes depending on the surface area of illite in the droplets. Droplets in the high surface area regime showed cooling rate dependent behaviour and the median freezing temperatures of these droplets did not depend on surface area. In comparison, freezing temperatures during cooling scaled with surface area for droplets in the low surface area regime. This variation in behaviour highlights the need to probe a range of conditions when performing nucleation experiments, in order to fully quantify the ice-nucleating ability of a particular IN.

The freezing temperatures of droplets in the low surface area regime $\left(s \leq 2 \times 10^{-6} \mathrm{~cm}^{2}\right)$ did not depend on cooling rate $\left(0.8-10.3 \mathrm{~K} \mathrm{~min}^{-1}\right)$. Hence, this data is well approximated by the time independent singular model. However, 
nucleation continued with time when the temperature was held constant, which is inconsistent with the singular model. This apparent contradiction could be reconciled if it was assumed that there was a distribution of nucleation sites dispersed between droplets, each with a nucleation rate coefficient which increased very steeply with decreasing temperature.

While the multiple component stochastic model can provide a physically realistic description of ice nucleation by a sample containing many types of nucleation site, it is computationally expensive. In many situations in the atmosphere, especially where cooling rates are rapid, freezing by NX illite can be approximated by the singular model. Further work should be done to understand under what conditions the time dependence of ice nucleation is important. It should also be noted that different materials have different cooling rate dependencies. NX illite appears to contain components with steep $\operatorname{d} \ln J / \mathrm{d} T$ slopes ( $>8$, based on our estimated reproducibility of $0.3 \mathrm{~K}$ ), while kaolinite was found to have a slope of 0.9 in a previous study (Murray et al., 2011b) and would be expected to have a significant cooling rate dependence with a shift of several degrees on a factor of 10 change in cooling rate.

Our experimental results suggest that Diehl and Wurzler's (2004) parameterisation for illite may not be an accurate description of immersion mode ice nucleation by all illite particles. Diehl and Wurzler's parameterisation is compared to our data in Fig. 3 and is consistent with the higher surface area data. Deihl and Wurzler (2004) assume that all illite particles are similarly efficient IN. However, we show that only rare particles $\left(1\right.$ in $\sim 10^{5}$ of the individual $20 \mathrm{~nm}$ NX illite particles) can nucleate ice at such high temperatures. Therefore, using Deihl and Wurzler's parameterisation in models to represent ice nucleation by illite may result in a substantial overestimation of ice production rates at higher temperatures. In fact, we show that heterogeneous freezing on many NX-illite particles does not compete with homogeneous freezing.

The mineralogy of NX illite is similar to that of atmospheric dust samples collected from remote areas (see Fig. 1). It is much closer in composition to natural samples than Arizona Test Dust, which is commonly used in atmospheric studies at present. Therefore, we suggest that NX illite may be a more appropriate proxy for atmospheric dust than Arizona Test Dust. However, the composition of NX illite appears to vary between shipments, so there would be some advantage to the community of using samples from a single homogenised and well characterised source.
Acknowledgements. The authors acknowledge the Natural Environment Research Council (NE/H001050/1) and the European Research Council (240449 - ICE) for financial support. We thank ParticlesCIC (particlescic.org) for their help with BET analysis.

Edited by: M. Petters

\section{References}

Alvarez-Puebla, R. A., dos Santos Jr, D. S., Blanco, C., Echeverria, J. C., and Garrido, J. J.: Particle and surface characterization of a natural illite and study of its copper retention, J. Coll. Interf. Sci., 285, 41-49, 2005.

Arnold, E., Merrill, J., Leinen, M., and King, J.: The effect of source area and atmospheric transport on mineral aerosol collected over the north pacific ocean, Global Planet Change, 18, 137-159, 1998.

Chester, R., Elderfield, H., Griffin, J. J., Johnson, L. R., and Padgham, C.: Eolian dust along the eastern margins of the atlantic ocean, Mar. Geol., 13, 91-105, 1972.

Connolly, P. J., Möhler, O., Field, P. R., Saathoff, H., Burgess, R., Choularton, T., and Gallagher, M.: Studies of heterogeneous freezing by three different desert dust samples, Atmos. Chem. Phys., 9, 2805-2824, doi:10.5194/acp-9-2805-2009, 2009.

Crosier, J., Bower, K. N., Choularton, T. W., Westbrook, C. D., Connolly, P. J., Cui, Z. Q., Crawford, I. P., Capes, G. L., Coe, H., Dorsey, J. R., Williams, P. I., Illingworth, A. J., Gallagher, M. W., and Blyth, A. M.: Observations of ice multiplication in a weakly convective cell embedded in supercooled mid-level stratus, Atmos. Chem. Phys., 11, 257-273, doi:10.5194/acp-11-257-2011, 2011.

de Boer, G., Morrison, H., Shupe, M. D., and Hildner, R.: Evidence of liquid dependent ice nucleation in high-latitude stratiform clouds from surface remote sensors, Geophys. Res. Lett., 38, L01803, doi:01810.01029/02010GL046016, 2010.

Delany, A. C., Parkin, D. W., Griffin, J. J., Goldberg, E. D., and Reimann, B. E. F.: Airborne dust collected at barbados, Geochim. Cosmochim. Ac., 31, 885-909, 1967.

DeMott, P. J.: Laboratory studies of cirrus cloud processes, in: Cirrus, edited by: Lynch, D. K., Sassen, K., Starr, D. C., and Stephens, G., Oxford University Press, Oxford, 102-135, 2002.

DeMott, P. J., Cziczo, D. J., Prenni, A. J., Murphy, D. M., Kreidenweis, S. M., Thomson, D. S., Borys, R., and Rogers, D. C.: Measurements of the concentration and composition of nuclei for cirrus formation, Proc. Natl. Acad. Sci. USA, 100, 14655-14660, 2003a.

DeMott, P. J., Sassen, K., Poellot, M. R., Baumgardner, D., Rogers, D. C., Brooks, S. D., Prenni, A. J., and Kreidenweis, S. M.: African dust aerosols as atmospheric ice nuclei, Geophys. Res. Lett., 30(14), 1732, doi:10.1029/2003GL017410, 2003 b.

DeMott, P. J., Prenni, A. J., Liu, X., Kreidenweis, S. M., Petters, M. D., Twohy, C. H., Richardson, M. S., Eidhammer, T., and Rogers, D. C.: Predicting global atmospheric ice nuclei distributions and their impacts on climate, Proceedings of the National Academy of Sciences of the United States of America, 107, 11217-11222, doi:10.1073/pnas.0910818107, 2010.

Denman, K. L., Brasseur, G., Chidthaisong, A., Ciais, P., Cox, P. M., Dickinson, R. E., Hauglustaine, D., Heinze, C., Holland, E., Jacob, D., Lohmann, U., Ramachandran, S., da Silva Dias, P. L., 
Wofsy, S. C., and Zhang, X.: Couplings between changes in the climate system and biogeochemistry, in: Climate change 2007: The physical science basis. Contribution of working group i to the fourth assessment report of the intergovernmental panel on climate change, edited by: Solomon, S., D. , M. Qin, Manning, Z., Chen, M., Marquis, K. B., Averyt, M. T., and Miller, H. L., Cambridge University Press, Cambridge, 2007.

Diehl, K. and Wurzler, S.: Heterogeneous drop freezing in the immersion mode: Model calculations considering soluble and insoluble particles in the drops, J. Atmos. Sci., 61, 2063-2072, 2004.

Diehl, K. and Wurzler, S.: Air parcel model simulations of a convective cloud: Bacteria acting as immersion ice nuclei, Atmos. Environ., 44, 4622-4628, 2010.

Durant, A. J. and Shaw, R. A.: Evaporation freezing by contact nucleation inside-out, Geophys. Res. Lett., 32, L20814, doi:10.1029/2005GL024175, 2005.

Dymarska, M., Murray, B. J., Sun, L. M., Eastwood, M. L., Knopf, D. A., and Bertram, A. K.: Deposition ice nucleation on soot at temperatures relevant for the lower troposphere, J. Geophys. Res., 111, D04204, doi:10.1029/2005JD006627, 2006.

Fornea, A. P., Brooks, S. D., Dooley, J. B., and Saha, A.: Heterogeneous freezing of ice on atmospheric aerosols containing ash, soot and soil, J. Geophys. Res., 114, doi:10.1029/2009JD011958, 2009.

Glaccum, R. A. and Prospero, J. M.: Saharan aerosol over the tropical north atlantic - mineralogy, Mar. Geol., 37, 295-321, 1980.

Hillier, S.: Use of an air brush to spray dry samples for $\mathrm{x}$-ray powder diffraction, Clay Miner., 34, 127-135, 1999.

Hillier, S.: Accurate quantitative analysis of clay and other minerals in sandstones by xrd: Comparison of a rietveld and a reference intensity ratio (rir) method and the importance of sample preparation, Clay Miner., 35, 291-302, 2000.

Hillier, S.: Quantitative analysis of clay and other minerals in sandstones by x-ray powder diffraction (xrpd), Int. Assoc. Sedimentol. Spec. Publ., 34, 213-251, 2003.

Hoffer, T. E.: A laboratory investigation of droplet freezing, J. Meteorol., 18, 766-778, 1961.

Hoose, C., Lohmann, U., Erdin, R., and Tegen, I.: The global influence of dust mineralogical composition on heterogeneous ice nucleation in mixed-phase clouds, Environ. Res. Lett., 3, 10.1088/1748-9236/3/2/025003, 2008

Hoose, C., Kristjánsson, J. E., Chen, J. P., and Hazra, A.: A classical-theory-based parameterization of heterogeneous ice nucleation by mineral dust, soot and biological particles in a global climate model, J. Atmos. Sci., J. Atmos. Sci,. 67, 2483-2503, doi:10.1175/2010JAS3425.1, 2010.

Kandler, K., Benker, N., Bundke, U., Cuevas, E., Ebert, M., Knippertz, P., Rodriguez, S., Schuetz, L., and Weinbruch, S.: Chemical composition and complex refractive index of saharan mineral dust at izana, tenerife (spain) derived by electron microscopy, Atmos. Environ., 41, 8058-8074, doi:10.1016/j.atmosenv.2007.06.047, 2007.

Kandler, K., Schutz, L., Jackel, S., Lieke, K., Emmel, C., MullerEbert, D., Ebert, M., Scheuvens, D., Schladitz, A., Segvic, B., Wiedensohler, A., and Weinbruch, S.: Ground-based off-line aerosol measurements at pria, cape verde, during the saharan mineral dust experiment: Microphysical properties and mineralogy, Tellus B, in press, 2011.
Kumar, R., Saunders, R. W., Mahajan, A. S., Plane, J. M.C., and Murray, B. J.: Physical properties of iodate solutions and the deliquescence of crystalline $\mathrm{I}_{2} \mathrm{O}_{5}$ and $\mathrm{HIO}_{3}$, Atmos. Chem. Phys., 10, 12251-12260, doi:10.5194/acp-10-12251-2010, 2010.

Lieke, K., Kandler, K., Scheuvens, D., Emmel, C., Glahn, C. v., Petzold, A., B., Weinzierl, Veira, A., Ebert, M., Weinbruch, S., and Schütz, L.: Particle chemical properties in the vertical column based on aircraft observations in the vicinity of cape verde islands, Tellus B, in press, 2011.

Lohmann, U. and Diehl, K.: Sensitivity studies of the importance of dust ice nuclei for the indirect aerosol effect on stratiform mixedphase clouds, J. Atmos. Sci., 63, 968-981, 2006.

Marcolli, C., Gedamke, S., Peter, T., and Zobrist, B.: Efficiency of immersion mode ice nucleation on surrogates of mineral dust, Atmos. Chem. Phys., 7, 5081-5091, doi:10.5194/acp-7-50812007, 2007.

Martin, S. T.: Phase transitions of aqueous atmospheric particles, Chem. Rev., 100, 3403-3453, 2000.

Mason, B. J.: The physics of clouds, Clarendon Press, Oxford, 1971.

Mohler, O., Benz, S., Saathoff, H., Schnaiter, M., Wagner, R., Schneider, J., Walter, S., Ebert, V., and Wagner, S.: The effect of organic coating on the heterogeneous ice nucleation efficiency of mineral dust aerosols, Environ. Res. Lett., 025007, 8 pp., doi:10.1088/1748-9326/3/2/025007, 2008.

Murray, B. J., Broadley, S., Wilson, T. W., Bull, S., and Wills, R.: Kinetics of the homogeneous freezing of water, Phys. Chem. Chem. Phys., 12, 10380-10387, doi:10310.11039/c003297b, 2010.

Murray, B. J., Broadley, S. L., and Morris, G. J.: Supercooling of water droplets in jet aviation fuel Fuel, 90, 433-435, doi:410.1016/j.fuel.2010.1008.1018 2011a.

Murray, B. J., Broadley, S. L., Wilson, T. W., Atkinson, J. D., and Wills, R. H.: Heterogeneous freezing of water droplets containing kaolinite particles, Atmos. Chem. Phys., 11, 4191-4207, doi:10.5194/acp-11-4191-2011, 2011 b.

Niedermeier, D., Hartmann, S., Shaw, R. A., Covert, D., Mentel, T. F., Schneider, J., Poulain, L., Reitz, P., Spindler, C., Clauss, T., Kiselev, A., Hallbauer, E., Wex, H., Mildenberger, K., and Stratmann, F.: Heterogeneous freezing of droplets with immersed mineral dust particles - measurements and parameterization, Atmos. Chem. Phys., 10, 3601-3614, doi:10.5194/acp-10-36012010, 2010.

Niedermeier, D., Shaw, R. A., Hartmann, S., Wex, H., Clauss, T., Voigtlnder, J., and Stratmann, F.: Heterogeneous ice nucleation: exploring the transition from stochastic to singular freezing behavior, Atmos. Chem. Phys., 11, 8767-8775, doi:10.5194/acp11-8767-2011, 2011.

Pant, A., Parsons, M. T., and Bertram, A. K.: Crystallization of aqueous ammonium sulfate particles internally mixed with soot and kaolinite: Crystallization relative humidities and nucleation rates, J. Phys. Chem. A, 110, 8701-8709, 2006.

Pratt, K. A., DeMott, P. J., French, J. R., Wang, Z., Westphal, D. L., Heymsfield, A. J., Twohy, C. H., Prenni, A. J., and Prather, K. A.: In situ detection of biological particles in cloud ice-crystals, Nat. Geosci., 2, 398-401, doi:310.1038/NGEO1521, 2009.

Pruppacher, H. R. and Klett, J. D.: Microphysics of clouds and precipitation, Kluwer, Dordrecht, 1997.

Richardson, M. S., DeMott, P. J., Kreidenweis, S. M., Cziczo, D. J., 
Dunlea, E. J., Jimenez, J. L., Thomson, D. S., Ashbaugh, L. L., Borys, R. D., Westphal, D. L., Casuccio, G. S., and Lersch, T. L.: Measurements of heterogeneous ice nuclei in the western united states in springtime and their relation to aerosol characteristics, J. Geophys. Res., 112, D02209, doi:10.1029/2006JD007500, 2007.

Shaw, R. A., Durant, A. J., and Mi, Y.: Heterogeneous surface crystallization observed in undercooled water, J. Phys. Chem. B, 109, 9865-9868, 2005.

Steudel, A., Batenburg, L. F., Fischer, H. R., Weidler, P. G., and Emmerich, K.: Alteration of non-swelling clay minerals and magadiite by acid activation, Appl. Clay Sci., 44, 95-104, 2009.

Stoyanova, V., Kashchiev, D., and Kupenova, T.: Freezing of water droplets seeded with atmospheric aerosols and ice nucleation activity of the aerosols, J. Aerosol Sci., 25, 867-877, 1994.
Vali, G. and Stansbury, E. J.: Time-dependent characteristics of the heterogeneous nucleation of ice, Can. J. Phys., 44, 477-502, 1966.

Vali, G.: Supercooling of water and nucleation of ice (drop freezer), Am. J. Phys., 39, 1125-1128, 1971.

Vali, G.: Nucleation terminology, Bull. Am. Met. Soc., 66, 1426, 1985.

Vali, G.: Freezing rate due to heterogeneous nucleation, J. Atmos. Sci., 51, 1843-1856, 1994.

Vali, G.: Repeatability and randomness in heterogeneous freezing nucleation, Atmos. Chem. Phys., 8, 5017-5031, doi:10.5194/acp-8-5017-2008, 2008. 